IUCrJ

ISSN 2052-2525

BIOLOGY|MEDICINE

Received 21 June 2021

Accepted 6 August 2021

Edited by K. Moffat, University of Chicago, USA

In memoriam of John Spence.

Keywords: substrate diffusion in crystals; antibiotic resistance; $\beta$-lactamases; enzyme kinetics; irreversible inhibition; mix-and-inject serial crystallography; serial femtosecond crystallography; European X-ray Free-Electron Laser; megahertz pulse-repetition rate; protein structure determination; drug discovery; ceftriaxone; sulbactam; X-ray crystallography; enzyme mechanisms.

PDB references: BlaC, unmixed, $7 \mathrm{k} 8 \mathrm{l}$; mixed with ceftriaxone, $5 \mathrm{~ms}, 7 \mathrm{k} 8 \mathrm{e}$; $10 \mathrm{~ms}, 7 \mathrm{k} 8 \mathrm{f}$; $50 \mathrm{~ms}, 7 \mathrm{k} 8 \mathrm{~h}$; mixed with sulbactam, $66 \mathrm{~ms}$, $7 \mathrm{k} 8 \mathrm{k}$

Supporting information: this article has supporting information at www.iucrj.org

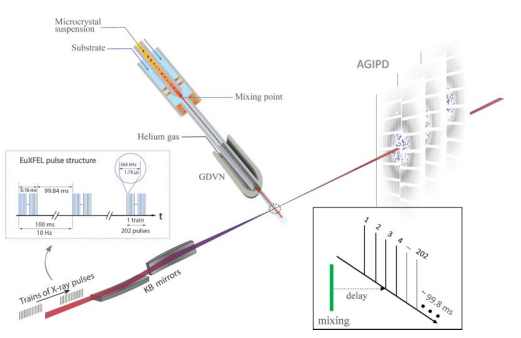
OPEN ๑ ACCESS

\section{Observation of substrate diffusion and ligand binding in enzyme crystals using high-repetition- rate mix-and-inject serial crystallography}

Suraj Pandey, ${ }^{a}$ George Calvey, ${ }^{b}$ Andrea M. Katz, ${ }^{\text {b }}$ Tek Narsingh Malla, ${ }^{\text {a }}$ Faisal H. M. Koua, ${ }^{c}$ Jose M. Martin-Garcia, ${ }^{\text {d,e }}$ Ishwor Poudyal, ${ }^{a}$ Jay-How Yang, ${ }^{\text {d }}$ Mohammad Vakili, ${ }^{\mathrm{f}}$ Oleksandr Yefanov, ${ }^{\mathrm{c}}$ Kara A. Zielinski, ${ }^{\mathrm{b}}$ Sasa Bajt, ${ }^{\mathrm{g}, \mathrm{h}}$ Salah Awel, ${ }^{\mathrm{c}}$ Katarina Doerner, ${ }^{f}$ Matthias Frank, ${ }^{i}$ Luca Gelisio, ${ }^{c}$ Rebecca Jernigan, ${ }^{d}$ Henry Kirkwood, ${ }^{f}$ Marco Kloos, ${ }^{\mathrm{f}}$ Jayanath Koliyadu, ${ }^{\mathrm{f}}$ Valerio Mariani, ${ }^{\mathrm{c}, \mathrm{j}}$ Mitchell D. Miller, ${ }^{\mathrm{k}}$ Grant Mills, ${ }^{f}$ Garrett Nelson, ${ }^{\prime}$ Jose L. Olmos Jr, ${ }^{k, m}$ Alireza Sadri, ${ }^{c}$ Tokushi Sato, ${ }^{f}$ Alexandra Tolstikova, ${ }^{\mathrm{c}}$ Weijun Xu, ${ }^{\mathrm{k}}$ Abbas Ourmazd, ${ }^{\mathrm{a}}$ John C. H. Spence, ${ }^{,}$Peter Schwander, ${ }^{\mathrm{a}}$ Anton Barty, ${ }^{\mathrm{g}}$ Henry N. Chapman, ${ }^{\mathrm{c}, \mathrm{h}, \mathrm{n}}$ Petra Fromme, ${ }^{\mathrm{d}}$ Adrian P. Mancuso, ${ }^{\text {f,o }}$ George N. Phillips Jr, ${ }^{\text {k, }}$ Richard Bean, ${ }^{\mathrm{f}}$ Lois Pollack $^{\mathrm{b}}$ and Marius Schmidt ${ }^{\mathrm{a} *}$

\footnotetext{
'Physics Department, University of Wisconsin-Milwaukee, 3135 North Maryland Avenue, Milwaukee, WI 53211, USA, ${ }^{\mathbf{b}}$ School of Applied and Engineering Physics, Cornell University, 254 Clark Hall, Ithaca, NY 14853, USA, ${ }^{\mathbf{c} C e n t e r}$ for Free-Electron Laser Science, Deutsches Elektronen-Synchrotron DESY, Notkestrasse 85, 22607 Hamburg, Germany, ${ }^{\mathbf{d}}$ School of Molecular Sciences and Biodesign Center for Applied Structural Discovery, Arizona State University, Tempe, AZ 85287-1604, USA, 'enstitute of Physical Chemistry Rocasolano, Spanish National Research Council, Calle de Serrano 119, 28006 Madrid, Spain, 'European XFEL, Holzkoppel 4, 22869 Schenefeld, Germany, ${ }^{\mathbf{g}}$ Deutsches ElektronenSynchrotron DESY, Notkestrasse 85, 22607 Hamburg, Germany, ${ }^{\mathbf{h}}$ The Hamburg Centre for Ultrafast Imaging, Luruper Chaussee 149, 22761 Hamburg, Germany, 'Lawrence Livermore National Laboratory, 7000 East Avenue, Livermore, CA 94550, USA, 'SLAC National Accelerator Laboratory, 2575 Sand Hill Rd, Menlo Park, California 94025, USA, kDepartment of BioSciences, Rice University, 6100 Main Street, Houston, TX 77005, USA, 'Department of Physics, Arizona State University, Tempe, AZ 85287, USA, 'mDepartment of Bioengineering and Therapeutic Sciences, University of California San Francisco, San Francisco, CA 94158, USA, "Department of Physics, Universität Hamburg, Luruper Chaussee 149, 22761 Hamburg, Germany, ${ }^{\circ}$ Department of Chemistry and Physics, La Trobe Institute for Molecular Science, La Trobe University, Melbourne, Victoria 3086, Australia, and ${ }^{\mathbf{P}}$ Department of Chemistry, Rice University, 6100 Main Street, Houston, TX 77005, USA. *Correspondence e-mail: m-schmidt@uwm.edu
}

Here, we illustrate what happens inside the catalytic cleft of an enzyme when substrate or ligand binds on single-millisecond timescales. The initial phase of the enzymatic cycle is observed with near-atomic resolution using the most advanced X-ray source currently available: the European XFEL (EuXFEL). The high repetition rate of the EuXFEL combined with our mix-andinject technology enables the initial phase of ceftriaxone binding to the Mycobacterium tuberculosis $\beta$-lactamase to be followed using time-resolved crystallography in real time. It is shown how a diffusion coefficient in enzyme crystals can be derived directly from the X-ray data, enabling the determination of ligand and enzyme-ligand concentrations at any position in the crystal volume as a function of time. In addition, the structure of the irreversible inhibitor sulbactam bound to the enzyme at a $66 \mathrm{~ms}$ time delay after mixing is described. This demonstrates that the EuXFEL can be used as an important tool for biomedically relevant research.

\section{Introduction}

Combatting the rise of infectious diseases requires a collaborative and interdisciplinary approach. Structural biologists can contribute by investigating the reaction mechanisms of biomedically significant enzymes as a structural basis to develop cures for diseases. Bacterial infections with strains that are resistant to currently available antibiotics are on the rise (Cassini et al., 2019). A study sponsored by the British government projected that in the near future more people will die from untreatable bacterial infections than from cancer (https://amr-review.org/). Bacterial enzymes that inactivate 
currently available drugs are central to antibiotic resistance (Fair \& Tor, 2014), and unraveling the catalytic mechanism of these enzymes will be beneficial for the development of novel antibiotics (Imming et al., 2006). $\beta$-Lactamases such as the Mycobacterium tuberculosis $\beta$-lactamase [BlaC; Fig. 1(a)] catalytically inactivate $\beta$-lactam antibiotics. $\beta$-Lactamases are responsible for the emergence of multidrug- and extensively drug-resistant bacterial strains (Smith et al., 2013). Infectious diseases that could be treated with antibiotics in the past may become untreatable. This warrants the investigation of the structure and function of these enzymes.

Using time-resolved crystallography, structures of intermediates and kinetic mechanisms can be extracted simultaneously from the same set of X-ray data (Moffat, 2001; Schmidt, 2008). At free-electron lasers (XFELs) small, micrometre- and submicrometre-sized, crystals can be examined due to the immense X-ray pulse intensity (Chapman $e t$ al., 2011). The microcrystals are destroyed by the pulses, and new crystals must be delivered to the X-ray interaction point in a serial fashion. This method has been termed serial femtosecond crystallography (SFX; Chapman et al., 2011; Boutet et al., 2012). Since the XFEL pulses are of femtosecond duration, diffraction patterns are collected before the crystals suffer significant radiation damage, resulting in X-ray structures that are essentially damage-free (Lomb et al., 2011; Nass, 2019; Neutze et al., 2000) and are suspended in their current reaction state. Most time-resolved crystallographic experi- ments at XFELs are of the pump-probe type. An optical laser pulse triggers a reaction in the crystallized molecules. Structures are probed by X-ray pulses after a controlled delay (Tenboer et al., 2014; Barends et al., 2015; Coquelle et al., 2018; Nogly et al., 2018; Kern et al., 2018; Pandey et al., 2019; Skopintsev et al., 2020; Dods et al., 2021; Yun et al., 2021). Due to the ultrashort nature of both X-ray and optical laser pulses, the experiments can reach subpicosecond time resolutions (Hartmann et al., 2014; Barends et al., 2015; Pande et al., 2016; Skopintsev et al., 2020). Photoactivation requires a lightsensitive cofactor, a chromophore, located in the protein to absorb the light. Light absorption must trigger a reaction that either promotes catalysis directly (Holtorf et al., 1995; Li et al., 2010; Sorigué et al., 2017, 2021) or regulates the activity of the enzyme (Takala et al., 2014; Gourinchas et al., 2017; Carrillo et al., 2021). Most enzymes, however, are neither activated nor regulated by light, meaning that the technique can only be directly applied in a narrow range of cases. Broader application requires great effort and chemical expertise to either engineer photoactive enzymes or to design photoactive compounds that can by soaked into, and activated in, enzyme crystals (Šrajer \& Schmidt, 2017; Zaitsev-Doyle et al., 2019; Mehrabi, Schulz, Dsouza et al., 2019).

With the 'mix-and-inject' technique (Schmidt, 2013; Stagno et al., 2017; Kupitz et al., 2017; Olmos et al., 2018; Mehrabi, Schulz, Agthe et al., 2019) photoactivation is not necessary. The substrate is rapidly mixed with small enzyme crystals

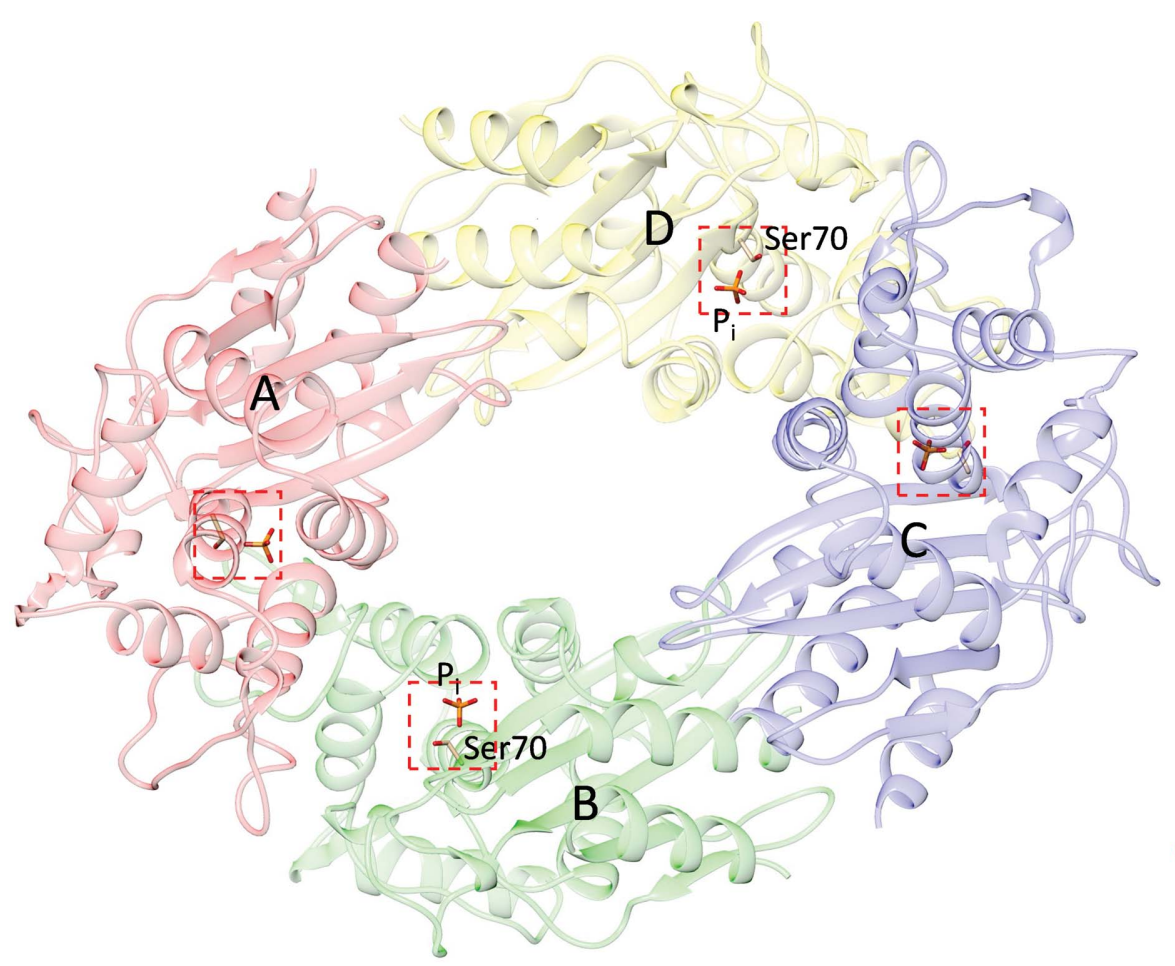

(a)

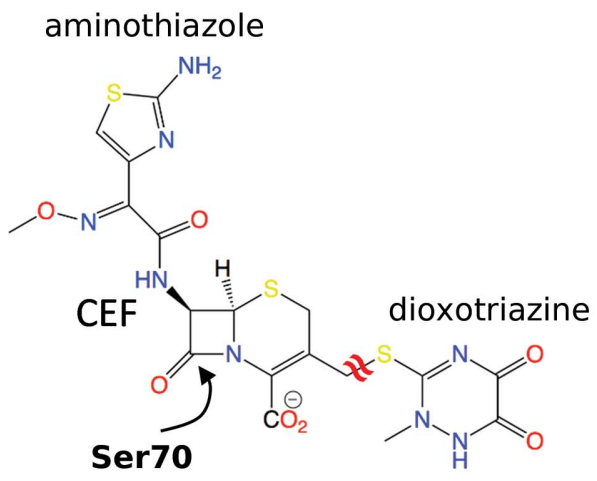

(b)

Figure 1

The structures of $\mathrm{BlaC}$ and the ligands investigated here. (a) Structure of $\mathrm{BlaC}$ in the orthorhombic crystal form. The four subunits of $\mathrm{BlaC}$ are shown in red $(A)$, green $(B)$, blue $(C)$ and yellow $(D)$. The red dotted box shows the position of the active site. A phosphate $\left(\mathrm{P}_{\mathrm{i}}\right)$ is present in all active sites. The catalytically active Ser70 is marked in subunits $B$ and $D$. (b) The chemical structure of ceftriaxone (CEF). The leaving group (dioxotriazine; the double tilde shows the cleaved bond) and the thiazole ring are marked. (c) The chemical structure of sulbactam (SUB). (d) The covalently bound trans-EN. Ser70 of BlaC opens the $\beta$-lactam ring of SUB. The structure rearranges to a trans-enamine. This inactivates BlaC. 
Table 1

Data-collection statistics [30 ms data from Olmos et al. (2018)].

\begin{tabular}{|c|c|c|c|c|c|c|}
\hline & Water (reference) & $5 \mathrm{~ms} \mathrm{CEF}$ & $10 \mathrm{~ms} \mathrm{CEF}$ & $50 \mathrm{~ms} \mathrm{CEF}$ & $66 \mathrm{~ms} \mathrm{SUB}$ & $30 \mathrm{~ms}$ CEF (LCLS) \\
\hline Temperature (K) & 293 & 293 & 293 & 293 & 293 & 293 \\
\hline Space group & $P 2_{1}$ & $P 2_{1}$ & $P 2_{1}$ & $P 2_{1}$ & $P 2_{1}$ & $P 2_{1}$ \\
\hline EuXFEL train pulse rate $(\mathrm{kHz})$ & 564 & 564 & 564 & 564 & 564 & 564 \\
\hline$a, b, c(\AA)$ & $80.9,99.5,112.6$ & $80.6,98.7,113.1$ & $80.6,98.5,113.5$ & $80.4,98.2,115.2$ & $81.0,99.5,112.6$ & $78.7,96.8,112.6$ \\
\hline$\alpha, \beta, \gamma\left({ }^{\circ}\right)$ & $90,108.4,90$ & $90,108.6,90$ & $90,108.8,90$ & $90,110.0,90$ & $90,108.4,90$ & $90,109.7,90$ \\
\hline Resolution $(\AA)$ & 2.8 & 2.4 & 2.6 & 2.6 & 2.7 & 2.7 \\
\hline Hits & 51980 & 110698 & 85775 & 85914 & 35886 & 35065 \\
\hline Indexed patterns & 31812 & 105495 & 52323 & 36256 & 25013 & 24397 \\
\hline Hit/indexing rate $(\%)$ & $2.98 / 61.2$ & $0.65 / 95.3$ & $1.33 / 61.0$ & $2.26 / 42.2$ & $0.78 / 69.7$ & $3.87 / 69.5$ \\
\hline Observed reflections & 31572191 & 114717921 & 49576617 & 38055135 & 21034155 & 14588166 \\
\hline Unique reflections & 41870 & 65232 & 51595 & 50760 & 45344 & 40340 \\
\hline Multiplicity & $754(236)$ & $1758(1246)$ & $966.3(580.4)$ & $749.7(449.4)$ & $463.8(307.4)$ & $526(142)$ \\
\hline Completeness (\%) & $100(100)$ & $100(100)$ & $100(100)$ & $100(100)$ & $100(100)$ & $100(100)$ \\
\hline$R_{\text {split }}(\%)$ & $20.6(988)$ & $15.6(303.7)$ & $17.8(334)$ & $20.9(198.1)$ & $21.4(459.2)$ & $14.2(121.1)$ \\
\hline $\mathrm{CC}_{1 / 2}(\%)$ & $96.5(22.9)$ & $99.2(26.9)$ & $99.6(58.4)$ & $99.5(58.4)$ & $96.9(20.5)$ & $98.6(34.5)$ \\
\hline
\end{tabular}

during sample delivery (Calvey et al., 2019). Mixing occurs at a well controlled location 'en route' to the X-ray beam. During the time delay $\Delta t_{\mathrm{m}}$ that occurs between mixing and injection, the substrate diffuses into the crystals and binds to the enzyme. The complex formed by the substrate and the enzyme then initiates the enzymatic cycle. Variation of $\Delta t_{\mathrm{m}}$ allows the measurement of rate coefficients together with atomic resolution structures which can be associated with intermediate states of the protein reactions (Kupitz et al., 2017; Olmos et al., 2018; Mehrabi, Schulz, Agthe et al., 2019). This can reveal the mechanism of enzyme action at the molecular level or the binding of a drug molecule. The combination of serial femtosecond crystallography with mixing before injection has been denoted 'mix-and-inject serial crystallography' (MISC; Kupitz et al., 2017; Olmos et al., 2018). The feasibility of MISC has previously been demonstrated with $\mathrm{BlaC}$ on longer millisecond timescales (Kupitz et al., 2017; Olmos et al., 2018). The observation of intermediate-state structures, and the maximization of the potential time resolution in both photoactivation and mix-and-inject techniques, relies on an accurately gauged start time of the reaction inside the crystals. In photoactivation experiments this requires a sufficient penetration of optical laser light into the crystal to ensure that a reaction is simultaneously triggered in a significant fraction of the molecules. In mix-and-inject experiments, the diffusion time of the substrate into the crystal may limit the ability to discriminate diffusion and kinetics, including substrate binding. To overcome this limitation, micrometre or submicrometre crystal sizes are required that ensure that the substrate diffuses rapidly into the crystals and the reaction is triggered swiftly and much faster than the lifetime of the reaction intermediates of interest (Schmidt, 2013).

The reaction of the cephalosporin antibiotic ceftriaxone [CEF; Fig. 1(b)] with BlaC is an excellent candidate for exploration with MISC. Previously, this reaction was investigated for $\Delta t_{\mathrm{m}}$ of longer than $30 \mathrm{~ms}$ (Kupitz et al., 2017; Olmos et al., 2018). At $30 \mathrm{~ms}$, however, the CEF binding sites in BlaC were essentially fully occupied (Olmos et al., 2018), a state also reached on similar timescales for other proteins and enzymes (Stagno et al., 2017; Mehrabi, Schulz, Agthe et al., 2019; Ishigami et al., 2019). The substrate-binding phase and the formation of the enzyme-substrate complex, however, remain elusive. Here, we aim to characterize the early phase of substrate binding with single-millisecond time delays by using the megahertz X-ray pulse-repetition rate of the European XFEL (EuXFEL; Decking et al., 2020).

In addition, we aim to investigate the reaction of $\mathrm{BlaC}$ with an inhibitor, sulbactam [SUB; Fig. 1(c)], on a millisecond timescale. The biochemistry of SUB and its application in combination with $\beta$-lactam antibiotics have been described in detail elsewhere (Totir et al., 2007). SUB binds to the active site of BlaC and reacts with the catalytically active serine of $\beta$-lactamases to form a covalently bound species. Most abundant is the so-called trans-enamine (trans-EN) species [Fig. 1(d)] that inhibits $\beta$-lactamases and helps to eliminate $\beta$-lactamase-induced antibiotic resistance. Static structures of trans-ENs with $\beta$-lactamases, including $\mathrm{BlaC}$, have recently been characterized (Cheng et al., 2020; Tassoni et al., 2019), but structures of the early species that form during SUB binding remain elusive.

\section{Methods}

\subsection{BlaC crystals}

Platelet-shaped crystals of $\mathrm{BlaC}$ with approximate dimensions of $10 \times 10 \times 2 \mu \mathrm{m}$ (Appendix $A$ ) were produced by a stirring method on site in the XBI facility of the EuXFEL (Han et al., 2021) using ammonium phosphate (AP) as described by Olmos et al. (2018). The crystals belonged to space group $P 2_{1}$ (Table 1), with four $\mathrm{BlaC}$ subunits in the asymmetric unit [Fig. 1(a)] (Olmos et al., 2018). Only two subunits bind CEF in their catalytic cleft, as demonstrated previously (Olmos et al., 2018). The concentration of BlaC subunits in the crystals is $15.5 \mathrm{~m} M$, so that the concentration of active subunits is $7.8 \mathrm{~m} M$. When this concentration is matched by substrate, the substrate concentration is called 'stoichiometric' in the following description.

\subsection{Data collection at the EuXFEL}

The platelets were mixed with ceftriaxone [CEF; Fig. 1(b); molecular mass $554.6 \mathrm{~g} \mathrm{~mol}^{-1}$; $200 \mathrm{~m} M$ in $0.8 M$ AP] or 
sulbactam (SUB) inhibitor [Fig. 1(c), molecular mass $223.2 \mathrm{~g} \mathrm{~mol}^{-1}, 100 \mathrm{mM}$ in $0.8 \mathrm{M} \mathrm{AP]}$ using optimized mixing injectors (Calvey et al., 2019) which were adapted to operate at the SPB/SFX instrument (Mancuso, 2019) of the EuXFEL. Flow rates and mixer geometries are shown in Table 2. The mixture was intercepted after a delay $\Delta t_{\mathrm{m}}$ by X-ray pulses from the EuXFEL. The EuXFEL delivers X-ray pulses in pulse trains that repeat ten times per second (Fig. 2). Each train contained $202 \mathrm{X}$-ray pulses with approximately 40 fs fullwidth at half-maximum (FWHM) pulse duration and about $1.5 \mathrm{~mJ}$ pulse energy. The pulse-repetition rate within a pulse train was $564 \mathrm{kHz}$, a reduction from the possible $4.5 \mathrm{MHz}$ to avoid pristine, upstream jet volumes being affected by previous X-ray pulses (Yefanov et al., 2019; Pandey et al., 2020; Grünbein et al., 2021). Given a flow rate of about $80 \mu \mathrm{min}^{-1}$ (Table 2) and an assumed jet diameter of $8 \mu \mathrm{m}$, the jet advances $26.5 \mathrm{~m}$ in a second. With a $564 \mathrm{kHz}$ pulse rate the jet is intercepted every $47 \mu \mathrm{m}$, which is much larger than the gap ( $\sim 20 \mu \mathrm{m}$; Wiedorn, Oberthür et al., 2018) in the jet produced by the intense X-ray pulse. The X-ray beam size at the jet position was $\sim 3 \mu \mathrm{m}$. The design of the mixers allowed us to recapture the record (Mehrabi, Schulz, Agthe et al., 2019) for the shortest MISC time point, while maintaining the high jet speed necessary for the $564 \mathrm{kHz}$ measurements (Wiedorn, Oberthür et al., 2018). Reference data were obtained by mixing with water.

Diffraction patterns (DPs) were collected using the Adaptive Gain Integrating Pixel Detector (AGIPD; Allahgholi et al., 2019) operating at a $565 \mathrm{kHz}$ frame rate. The experiment was monitored using $O n D A$ (Mariani et al., 2016), which is designed to estimate hit rates and spatial resolution in real time. DPs with Bragg reflections were selected by Cheetah (Barty et al., 2014) and indexed, integrated, scaled and merged by CrystFEL (White et al., 2016) in a manner consistent with previous work (Pandey et al., 2020). In brief, diffraction images with Bragg reflections were found by Cheetah (peakfinder8, minSNR=8, minADC=200, minPix=1, minPeaks=25) using the calibration process described by Wiedorn, Awel et al. (2018). Careful masking of shadowed and unreliable regions of the detector was performed on a run-by-run basis (Appendix $B$ ). Independent masks were used for peak finding to avoid false hits, for example due to ice formation. Indexing

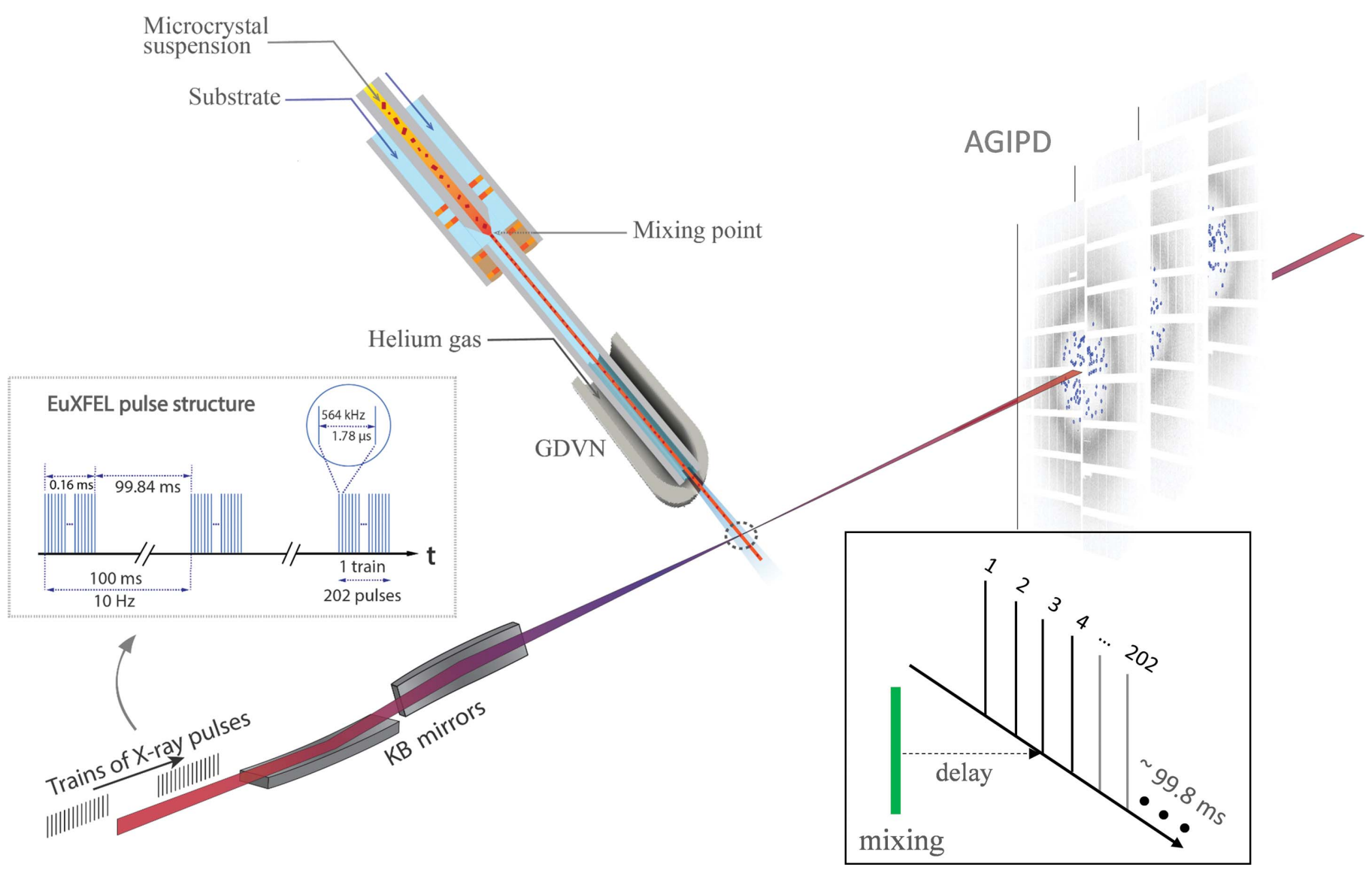

Figure 2

Experimental setup at the European XFEL. BlaC microcrystals are mixed with substrate and injected into the X-ray interaction region (dotted circle) after a delay determined by the distance between the mixing region and the X-rays, the capillary width and the flow rate. Diffusion of substrate into the crystals occurs during this time. The mixture is probed by trains of X-ray pulses. The trains repeat ten times per second. Pulses within the trains repeat at $564 \mathrm{kHz}$, hence the pulses are spaced by $1.78 \mu \mathrm{s} .202$ pulses were in each train for this experiment. The AGIPD collects the diffraction patterns and reads them out for further analysis. Inset: data collection. With a selected injector geometry and flow rate, the delay is fixed by the distance of the mixing region from the X-ray interaction region. All pulses in all trains (here pulse 3) probe the same time delay. The EuXFEL pulse structure is most efficiently used. 
Table 2

Parameters for the mix-and-inject experiments.

Concentrations of ceftriaxone (CEF) and sulbactam (SUB) are shown as were flowed through the outer capillary line of the mixing injectors. Time delays are achieved after mixing in a constriction as per Calvey et al. (2019).

\begin{tabular}{|c|c|c|c|c|c|}
\hline & Water & SUB & $\mathrm{CEF}$ & CEF & $\mathrm{CEF}$ \\
\hline Ligand concentration $(\mathrm{m} M)$ & - & 100 & 200 & 200 & 200 \\
\hline Ligand buffer & - & $0.8 \mathrm{M}$ AP pH 4.6 & $0.8 \mathrm{M}$ AP pH 4.6 & $0.8 \mathrm{M} \mathrm{AP} \mathrm{pH} 4.6$ & $0.8 \mathrm{M} \mathrm{AP} \mathrm{pH} 4.6$ \\
\hline Crystal flow $\left(\mu 1 \min ^{-1}\right)$ & 5.5 & 11.6 & 3.3 & 5.5 & 8.2 \\
\hline Mixing injector capillary internal diameter $(\mu \mathrm{m})$ & 50 & 75 & 50 & 50 & 75 \\
\hline Constriction length (mm) & 17.8 & 36.1 & 9.3 & 17.8 & 36.1 \\
\hline
\end{tabular}

was performed with CrystFEL (version 0.9.0) using the indexing package $X G A N D A L F$ (Gevorkov et al., 2019) with the following parameters: peaks=peakfinder8, Min$\mathrm{SNR}=5$, Min-pixel-count=1, Threshold=400. The detector geometry was refined using geoptimiser (Yefanov et al., 2015). Merging and scaling of the Bragg peak intensities were performed using the partialator program from CrystFEL. To avoid the integration of noise for weakly scattering patterns, reflections were included up to $1.0 \mathrm{~nm}^{-1}$ above a conservative resolution estimate for each crystal (--pushres $=1.0)$. Hit rates and indexing rates were stable in the order of $1.0 \%$ and $70 \%$, respectively, irrespective of the pulse index in the train (Appendix $A$ ). The lower hit rate is a consequence of diluting the crystalline slurry with the ligand/ substrate. It has been shown that the X-ray pulse position in the train has no effect on the structure (Yefanov et al., 2019). Structure-factor amplitudes were generated from the measured intensities using programs from the $C C P 4$ software suite (Winn et al., 2011). Data-collection statistics are shown in Table 1.

As a control, and to investigate the result of the complete reaction of BlaC with SUB in the platelet crystal form, macroscopic crystals were grown in sitting drops $(10 \mu \mathrm{l} \mathrm{BlaC}$ at $45 \mathrm{mg} \mathrm{ml}^{-1}$ mixed in a 1:1 ratio with $2.1 M$ AP $\mathrm{pH} 4.1$ ). Crystals grew within three days. The crystals were soaked for $3 \mathrm{~h}$ in a cryobuffer consisting of $2 M$ AP, $20 \%$ glycerol and $100 \mathrm{~m} M$ SUB. The crystals were cooled in liquid nitrogen. Data were collected on beamline ID-19 of the Structural Biology Center, Advanced Photon Source, Argonne National Laboratory. Data were processed to $2.7 \AA$ using $H K L-3000$ (Minor et al., 2006). Details will be presented elsewhere.

\subsection{Difference-map calculation and structure determination}

The structures of BlaC and the BlaC-CEF complexes were determined as described previously (Kupitz et al., 2017; Olmos et al., 2018). Since the unit-cell constants change substantially after mixing (Table 1), isomorphous difference maps cannot be calculated and OMIT difference maps $\left(\mathrm{DED}_{\text {omit }}\right)$ were used. An initial BlaC model, PDB (Berman et al., 2002) entry 6b5x (Olmos et al., 2018), was refined against the structurefactor amplitudes $\left|F_{\mathrm{o}}(t)\right|_{\mathrm{CEF}}$ collected at a particular $\Delta t_{\mathrm{m}}$. The content of the active sites (water and phosphate) was removed during the refinement. From the refined model amplitudes, $\left|F_{\mathrm{c}}\right|$ were determined. From the amplitudes (and the phases obtained from the refined model), weighted $m\left|F_{\mathrm{o}}(t)\right|_{\mathrm{CEF}}-$ $D\left|F_{\text {c }}\right|$ OMIT maps $\left(\mathrm{DED}_{\text {omit }}\right)$ were calculated. Polder differ-


to display weak difference electron-density features. The CEF was modeled in the polder maps. To refine the structure and to determine the fractional concentration of both $\mathrm{P}_{\mathrm{i}}$ and CEF, grouped occupancy refinement was performed using Phenix (Liebschner et al., 2019). CEF was flagged together with $\mathrm{P}_{\mathrm{i}}$ as a pair of molecules occupying the same space. The positions and $B$ factors of all atoms as well as the occupancies of $\mathrm{P}_{\mathrm{i}}$ and CEF were refined simultaneously. As a check, the sum of the occupancies of the flagged molecules should not deviate too much from unity.

Initial structures of the BlaC-SUB complexes were determined by inspecting both isomorphous and OMIT difference maps. The OMIT map was calculated in a similar way as described above except that amplitudes $\left|F_{\mathrm{o}}(t)\right|_{\text {SUB }}$ were used. A weighted $\mathrm{DED}_{\text {iso }}$ map was calculated from difference amplitudes $w\left[\left|F_{\mathrm{o}}(t)\right|_{\mathrm{SUB}}-\left|F_{\mathrm{o}}\right|_{\mathrm{WAT}}\right]$, where the reference

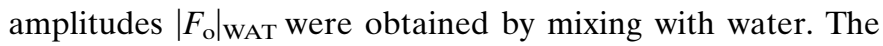
weighting factor was calculated as described previously for photoactive yellow protein (Ren et al., 2001; Pandey et al., 2020) and for the needle crystal form of BlaC (Olmos et al., 2018). The trans-EN and SUB molecules were inserted into the OMIT map. The positions and orientations were crossexamined to agree with the $\mathrm{DED}_{\text {iso }}$ map. The complexes were refined using REFMAC (Murshudov et al., 2011) against the $\left|F_{\mathrm{o}}(t)\right|_{\text {SUB }}$ amplitudes. The refinement statistics for the BlaCCEF and BlaC-SUB complexes are shown in Table 3.

\subsection{Binding kinetics of CEF}

Refined occupancies are fitted by functions that account for saturation of CEF and decline of $\mathrm{P}_{i}$,

$$
C_{\mathrm{CEF}}(t)=\frac{C_{\mathrm{S}, \mathrm{CEF}} \cdot t}{t_{1 / 2}+t},
$$

and

$$
C_{\mathrm{P}_{\mathrm{i}}}(t)=\frac{C_{\text {ini, } \mathrm{P}_{\mathrm{i}}} \cdot t_{1 / 2}}{t_{1 / 2}+t},
$$


Table 3

Refinement statistics.

\begin{tabular}{lllllll}
\hline & Water & $5 \mathrm{~ms}$ CEF & $10 \mathrm{~ms}$ CEF & $50 \mathrm{~ms}$ CEF & $66 \mathrm{~ms}$ SUB & $30 \mathrm{~ms}$ CEF (Olmos et al., 2018, revisited) \\
\hline Refinement program & Phenix & Phenix & Phenix & Phenix & REFMAC & Phenix \\
Resolution & 2.8 & 2.4 & 2.6 & 2.6 & 2.7 & 2.75 \\
Reflections used & 36804 & 52163 & 43274 & 45264 & 36434 & 40951 \\
$R_{\text {cryst }} / R_{\text {free }}$ & $0.21 / 0.27$ & $0.24 / 0.25$ & $0.22 / 0.26$ & $0.22 / 0.27$ & $0.21 / 0.29$ & $0.22 / 0.26$ \\
Occupancy $(\mathrm{CEF} /$ phosphate $)(\%)$ & - & $B, 46 / 60 ; D, 43 / 53$ & $B, 61 / 35 ; D, 64 / 38$ & $B, 84 / 11 ; D, 79 / 27$ & 100, not refined $B, 76 / 20 ; D, 74 / 21$ \\
$\langle B\rangle_{\text {CEF }}(B / D)\left(\AA^{2}\right)$ & - & $51 / 48$ & $55 / 58$ & $53 / 50$ & - & $70 / 67$ \\
R.m.s.d., bond lengths $\left(\AA^{2}\right)$ & 0.009 & 0.003 & 0.003 & 0.003 & 0.007 & 0.003 \\
R.m.s.d., bond angles $\left({ }^{\circ}\right)$ & 1.09 & 1.07 & 1.03 & 1.34 & 1.67 & 1.10 \\
$\mathrm{H}_{2} \mathrm{O}$ & 129 & 246 & 251 & 247 & 201 & 146 \\
\hline
\end{tabular}

respectively. $C_{\mathrm{S}, \mathrm{CEF}}$ and $C_{\text {ini, } \mathrm{P}_{\mathrm{i}}}$ are the occupancy of CEF after a long time (at saturation) and the initial occupancy of $\mathrm{P}_{\mathrm{i}}$, respectively. The constant $t_{1 / 2}$ is either the time taken to reach half saturation of CEF or denotes the time when $\mathrm{P}_{i}$ has declined to half its initial concentration. The initial occupancy of $\mathrm{P}_{\mathrm{i}}$ was set as 1.0, but the final occupancy of CEF was not constrained to 1.0 to account for a more realistic scenario.

\subsection{The diffusion coefficient of CEF in the BlaC platelets}

The occupancy of CEF bound noncovalently to the active center of BlaC was calculated with typical sized $10 \times 10 \times$ $2 \mu \mathrm{m}$ (platelet-like) crystals (Appendix $A$ ) by varying the diffusion coefficient $D$ for the CEF in crystals until agreement with the experiment was achieved. The crystal was divided into 20 voxels along each direction and 20 time intervals were used. For each time interval, the concentration of the CEF substrate $\left(C_{\mathrm{CEF}}\right)$ in each of the 8000 voxels in the crystal was determined using the known solution to Fick's second law for a rectangular volume, represented by the first 20 modes (Schmidt, 2013, 2020; Carslaw \& Jaeger, 1959),

$$
\begin{aligned}
& C_{\mathrm{CEF}}(x, y, z, t)= \\
& C_{0, \mathrm{CEF}}\left(1-\frac{64}{\pi^{3}} \sum_{l=0}^{19} \sum_{m=0}^{19} \sum_{n=0}^{19} \frac{(-1)^{l+m+n}}{(2 l+1)(2 m+1)(2 n+1)}\right. \\
& \quad \times \cos \frac{(2 l+1) \pi x}{2 a} \cos \frac{(2 m+1) \pi y}{2 b} \cos \frac{(2 n+1) \pi z}{2 c} \\
& \left.\quad \times \exp \left\{-\frac{D \pi^{2}}{4}\left[\frac{(2 l+1)^{2}}{a^{2}}+\frac{(2 m+1)^{2}}{b^{2}}+\frac{(2 n+1)^{2}}{c^{2}}\right] t\right\}\right),
\end{aligned}
$$

where $l, m, n$ are integer numbers that define the modes. $x, y$ and $z$ are coordinates within the crystal that extend from $-a$ to $+a,-b$ to $+b$ and $-c$ to $c$, where $a, b, c$ are the half edge lengths of the platelet-shaped BlaC crystals. $D$ is the diffusion coefficient, $t$ is the time after mixing and $C_{0, \mathrm{CEF}}$ is the outside CEF concentration, which was set to $150 \mathrm{~m} M$. This analytical approach to diffusion is strictly speaking only valid in the absence of substrate binding. However, here the substrate concentration $(\sim 150 \mathrm{mM})$ is much higher than the concentration of the subunits that bind the CEF $(7.8 \mathrm{mM})$. The concentration of substrate in the crystals increases rapidly to values much higher than the stoichiometric concentration. At saturation, the ES concentration is only $5.2 \%$ of that of the substrate. In addition, the speed (rate) of substrate binding is low until sufficient substrate is present. Accordingly, substrate binding is a small perturbation of the free CEF concentration on all but the very shortest timescales.

On the timescales employed here, the formation of later intermediates and the catalytic turnover of BlaC with CEF do not play a role (Boyd \& Lunn, 1979; Hugonnet \& Blanchard, 2007; Tremblay et al., 2010; Olmos et al., 2018). Both processes unfold over much longer timescales (Fig. 3) than the time delays examined here.

CEF binding to the active sites of BlaC is dependent on the free $\mathrm{BlaC}$ concentration in the crystal and the rate coefficients that describe the binding kinetics (Fig. 3). Here, the rate coefficient $k_{\text {on }}$ of $3.2 M^{-1} \mathrm{~s}^{-1}$ as estimated by Olmos and coworkers was used. The $k_{\text {off }}$ rate coefficient (dashed arrow in Fig. 3) was assumed to be negligible relative to the on-rate coefficient. There is only one free parameter, the diffusion coefficient $D$, which can be inferred by matching calculated occupancies to the refined occupancies observed at $\Delta t_{\mathrm{m}}$. (3) provides substrate (CEF) concentrations in each individual voxel (at each position in the crystal) at any particular time $t$. $\mathrm{CEF}$ binding to $\mathrm{BlaC}$ was calculated for each voxel by numerically integrating the rate equation with time intervals $\mathrm{d} t$,

$$
\begin{aligned}
\mathrm{d}[\mathrm{ES}] & =\left[\mathrm{E}\left(t_{i}\right)\right]_{\text {free }} \cdot\left[C_{\mathrm{CEF}}\left(t_{i}\right)\right] \cdot k_{\text {on }} \mathrm{d} t, \\
{\left[\mathrm{ES}\left(t_{i+1}\right)\right] } & =\left[\mathrm{ES}\left(t_{i}\right)\right]+\mathrm{d}[\mathrm{ES}], \\
{\left[\mathrm{E}\left(t_{i+1}\right)\right]_{\text {free }} } & =\left[\mathrm{E}\left(t_{i}\right)\right]_{\text {free }}-\mathrm{d}[\mathrm{ES}], \\
t_{i+1} & =t_{i}+\mathrm{d} t
\end{aligned}
$$

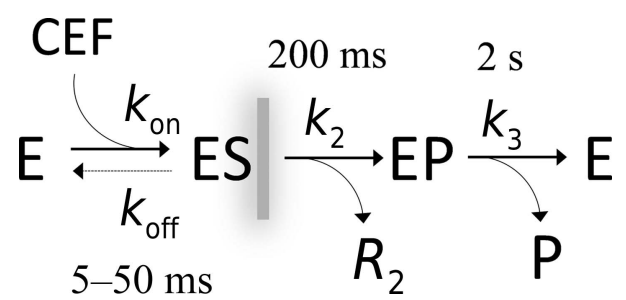

Figure 3

Simplified enzymatic cycle of, and the timescales associated with, the reaction of $\mathrm{BlaC}$ with CEF. CEF is delivered to the crystals by diffusion. It noncovalently binds to the free BlaC enzyme (E) to form the enzymesubstrate complex (ES). The acyl intermediate EP, which is covalently bound to Ser70, is formed within $\sim 200 \mathrm{~ms}$. The leaving group $R_{2}$ is cleaved off the CEF. The modified CEF (EP) is hydrolyzed and released as product $(\mathrm{P})$ and the free enzyme is recovered within about $2 \mathrm{~s}$. In this paper, only the formation of the ES complex up to $50 \mathrm{~ms}$ (gray, blurred vertical line) was explored. 
In (4), d[ES] is the change in concentration of the BlaC-CEF complex ([ES]) given the free enzyme ([E]) and free CEF ([C $\left.\left.C_{\mathrm{CEF}}\right]\right)$ concentrations at time $t_{i}$ and the $k_{\mathrm{on}}$ rate. The freeenzyme concentration [E] decreases and that of the BlaCCEF complex increases with each time step. (4) is repeated by increasing $t_{\mathrm{i}}$ by $\mathrm{d} t$ until $t_{i}$ is larger than a given delay time, for example $10 \mathrm{~ms}$. The substrate $\left[C_{\mathrm{CEF}}\right]$ is provided everywhere by diffusion (3) and its concentration is also dependent on $t_{i}$. The goal was to reproduce the approximate $50 \% \mathrm{BlaC}-\mathrm{CEF}$ occupancy in the $B$ and $D$ subunits (occ ${ }_{\mathrm{obs}}$ ) which was observed in the experiment at around $5 \mathrm{~ms}$. The calculated BlaC-CEF occupancy ( occ $_{\text {calc }}$ ) is the average of the calculated occupancies found in all voxels of the crystal. Occ calc $_{\text {can }}$ can then be compared with occ $\mathrm{obs}_{\mathrm{o}}$ and adjusted by varying the diffusion coefficient of CEF.

\section{Results and discussion}

\subsection{Formation of the enzyme-substrate complex}

The EuXFEL $564 \mathrm{kHz}$ pulse structure was used to measure the binding of the large CEF substrate to $\mathrm{BlaC}$ at a $\Delta t_{\mathrm{m}}$ of 5 , 10 and $50 \mathrm{~ms}$. The $\Delta t_{\mathrm{m}}$ of $5 \mathrm{~ms}$ is about an order of magnitude faster than the earliest $(30 \mathrm{~ms})$ time point collected previously (Olmos et al., 2018). The $\sim 2 \mu \mathrm{m}$ thin, platelet-shaped BlaC microcrystals allow fast diffusion times across the thin dimension. Furthermore, diffusion is facilitated by large channels in the crystals (Olmos et al., 2018). Therefore, these crystals are ideally suited for mix-and-inject investigations on fast timescales.

As observed in the previous studies at longer $\Delta t_{\mathrm{m}}$, CEF only binds to BlaC subunits $B$ and $D$. In Figs. 4(b)-4(d) polder difference electron-density maps (Liebschner et al., 2017; $\mathrm{DED}_{\text {Polder }}$ ) are shown in the active site of subunit $B$. On early timescales (5 and $10 \mathrm{~ms}$ after mixing) we simultaneously observe electron densities for CEF and the close-by phosphate $\left(P_{i}\right)$ molecule. Since CEF and $P_{i}$ occupy the same space, their presence is mutually exclusive and the electron density reflects an average over sites occupied by $\mathrm{P}_{\mathrm{i}}$ and others occupied by CEF. $P_{i}$ is also found near the CEF binding site in the unliganded (unmixed) form [Fig. 4(a)]. At $\Delta t_{\mathrm{m}}=5 \mathrm{~ms}$, the $\mathrm{P}_{\mathrm{i}}$ and CEF occupancies are both approximately $50 \%$. The available catalytic sites in subunits $B$ and $D$ are equally occupied either by a CEF or by a $\mathrm{P}_{\mathrm{i}}$. At $\Delta t_{\mathrm{m}}=50 \mathrm{~ms}$, the $\mathrm{P}_{\mathrm{i}}$ density vanishes. Nevertheless, the $\mathrm{P}_{\mathrm{i}}$ occupancy refines to $19 \%$ and that of CEF to $82 \%$ (Table 3 ). Here, an electron-rich compound $\left(\mathrm{P}_{\mathrm{i}}\right)$ is refined in conjunction with $\mathrm{CEF}$, occupying equivalent spaces in different unit cells. This may result in an overestimate of the occupancy of $\mathrm{P}_{\mathrm{i}}$. As there is no indication of phosphate-shaped electron density at $50 \mathrm{~ms}[\mathrm{Fig} .4(d)]$, we consider this to be the error margin of our occupancy refinement.

In agreement with previous work (Olmos et al., 2018), an additional CEF molecule is identified close to each active site that weakly interacts (stacks) with the CEF already bound there (Fig. 5). The stacking sites seem to be only transiently visited by CEF molecules until the active sites are fully occupied. The unit-cell parameter changes roughly follow CEF binding and $\mathrm{P}_{\mathrm{i}}$ release [Fig. 6(a), inset; Table 1]. When sulbactam, which is about 2.5 times smaller, binds the $P_{i}$ is not replaced and the unit-cell parameters do not change (see below and Table 1). We postulate that the displacement of the strongly negatively charged $\mathrm{P}_{\mathrm{i}}$, as well as the occupancy of the stacking site, may contribute to the unit-cell changes observed when CEF is mixed in. The needle crystal form described earlier (Olmos et al., 2018) does not show unit-cell changes. There, neither the $P_{i}$ nor the stacking site is present. In our $\mathrm{BlaC}$ platelets the CEF occupancy can be very heterogenous, in particular at $5 \mathrm{~ms}$, which should result in different unit-cell parameters near the surface and in the center, respectively. However, the Bragg reflections are not split, which is in accordance with observations by others (Ramakrishnan et al., 2021; Stagno et al., 2017; Kupitz et al., 2014). This may be a consequence of the fully coherent illumination of the entire microcrystal volume by the XFEL radiation or may be due to the plasticity of microcrystals that even supports phase transitions and space-group changes (Ramakrishnan et al., 2021).

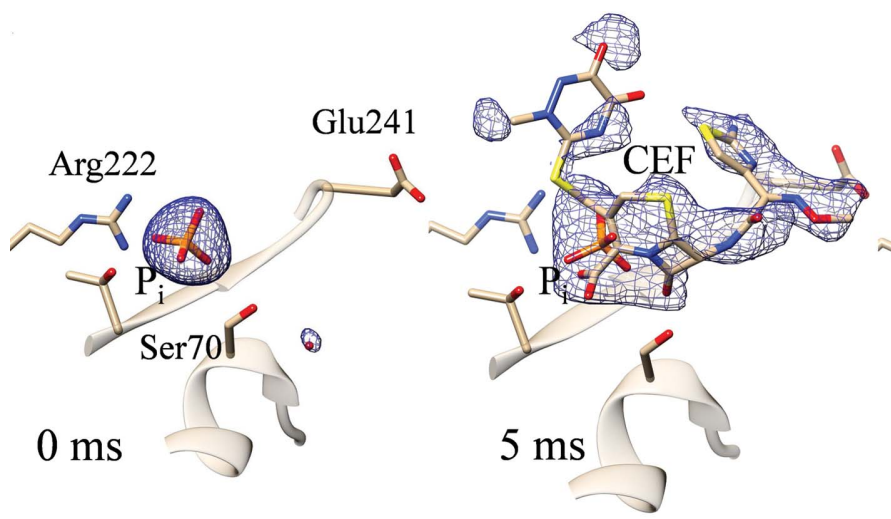

(a)

(b)



(c)



(d)

Figure 4

Polder difference electron density, contour level $3 \sigma$, in the active center of BlaC subunit $B$. (a) The CEF ligand has not yet diffused in; the phosphate ( $\mathrm{P}_{\mathrm{i}}$ ) from the crystallization buffer is dominant in the active site. (b) $5 \mathrm{~ms}$ after mixing: the phosphate is beginning to be displaced by CEF. (c) $10 \mathrm{~ms}$ after mixing: the phosphate is no longer dominant. (d) $50 \mathrm{~ms}$ after mixing: little evidence of the phosphate remains and the density only has features of the antibiotic compound. Nearby amino acids are marked in $(a)$. 
As more CEF binds, Ser70 moves towards the $\mathrm{P}_{\mathrm{i}}$ position (by about $1 \AA$ ) and the $P_{i}$ is replaced at the same time (Table 4c). Other amino acids such as Asn172 and Asp241 move closer to the CEF. We can now develop a mini-movie for the formation of an enzyme-substrate (ES) complex (Supplementary Movie S1). This movie visualizes how CEF interacts with BlaC. The initial binding phase is complete when the CEF occupancy approaches saturation. Since the aminothiazole ring and, in particular, the dioxotriazine ring of
CEF stick out from the center [the $\beta$-lactam ring fused to the six-membered thiazine ring; Fig. 1(b)], they are more disordered and their electron densities are weaker. However, clear density features guide a structural refinement that shows that CEF binds through a succession of conformations which may be associated with distinct $\mathrm{BlaC}$ intermediates. The separation of these intermediates from the X-ray data is difficult since we have not collected a sufficiently large number of time delays to apply meaningful deconvolution algorithms (Schmidt et al.,



(a)

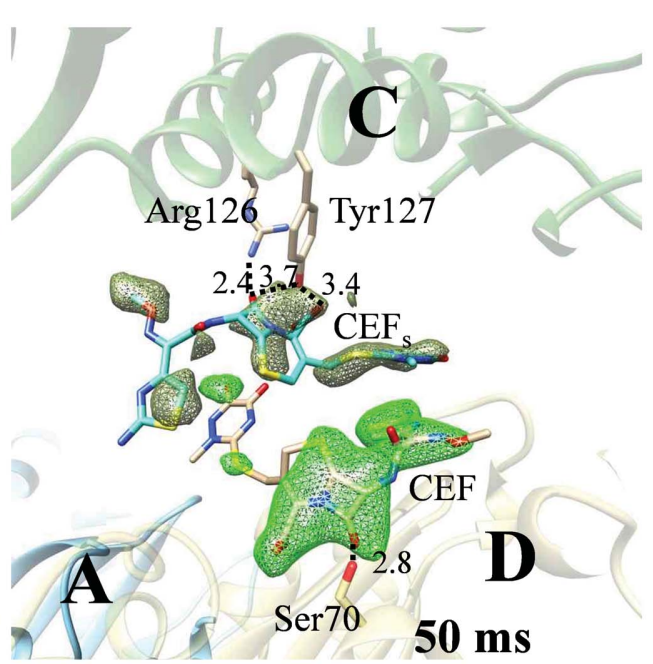

(b)



$(c)$

Figure 5

Additional ligands. (a) $\mathrm{CEF}$ in the active site and the stacking site (dotted oval) located between subunits $D$ and $C$. A $D F_{\mathrm{o}}-m F_{\mathrm{c}}$ OMIT difference electron-density map in the active site is shown in green and that in the stacking site in gray-green (at a $2.5 \sigma$ contour level). Substantial CEF density in the active site is shown in green. There is also electron density for $\mathrm{P}_{\mathrm{i}}$ present due to averaging over all unit cells in the crystal. The stacking site is not occupied (gray $\mathrm{CEF}_{\mathrm{s}}$ molecule). (b) At $50 \mathrm{~ms}$ the maximum occupancy of CEF in the active center is reached. The stacking site is substantially occupied (blue CEF molecule). Important residues and distances are marked in $\AA$. (c) The covalently bound trans-EN is present in subunit $A$ of the static cryostructure of BlaC when soaked with SUB (blue; $2 F_{\mathrm{o}}-F_{\mathrm{c}}$ map at a $1.5 \sigma$ contour level).



(a)

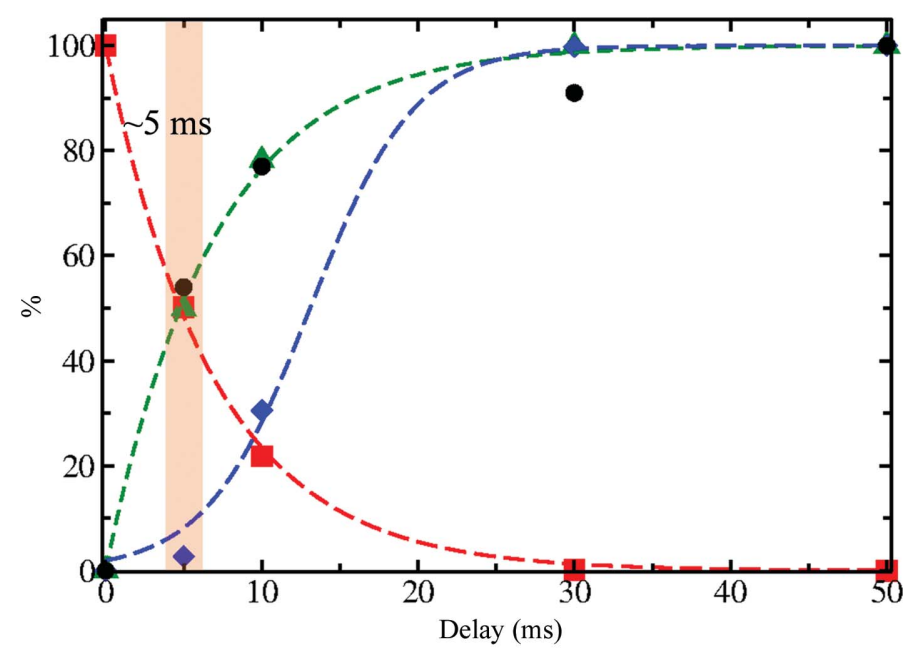

(b)

Figure 6

BlaC-CEF complex formation as a function of time. (a) Occupancies of CEF in the active site of BlaC at 5, 10, 30 and $50 \mathrm{~ms}$ in subunits $B$ (spheres) and $D$ (squares) as well as those of $\mathrm{P}_{\mathrm{i}}$ (green triangles and blue diamonds) are plotted as a function of delay (the $30 \mathrm{~ms}$ data are from Olmos et al., 2018). The data are fitted with saturation curves [equations (1) and (2), black and blue dashed lines]. The two curves intersect at around 6 ms. Inset: the corresponding change in the unit-cell axis $c$. (b) Concentrations (in \%) as calculated from diffusion and binding [equations (1)-(5)]; green dashed line and green triangles, increase of the calculated BlaC-CEF complex concentration averaged over all voxels in the crystal; red dashed line and squares, decrease of the free enzyme (BlaC); blue dashed line and diamonds, increase of the BlaC-CEF complex in the center of the platelet-shaped crystals. For comparison, the observed (refined) occupancies of the BlaC-CEF complex (normalized to $100 \%$ at $50 \mathrm{~ms}$ ) are also shown (black spheres). 
Table 4

Important distances in the active centers of BlaC.

s, strong hydrogen bond up to $2.5 \AA$; h, hydrogen bond from 2.6 to $3.2 \AA$; w, weak interaction $>3.2 \AA$ (Jeffrey, 1997).

(a) Distances in ( $\AA$ ) in subunits $A$ and $C$ to the sulbactam (0RN).

\begin{tabular}{lll}
\hline & Subunit $A$ & Subunit $C$ \\
\hline Ser70 OG to $P_{\mathrm{i}} \mathrm{O}$ & $3.2(\mathrm{~h})$ & $2.6(\mathrm{~h})$ \\
Ser70 OG to 0RN OAF & $3.1(\mathrm{~h})$ & $3.2(\mathrm{~h})$ \\
Gln112 OE1 to 0RN OX & Gln from $B, 2.8(\mathrm{~h})$ & Gln from $D, 3.3(\mathrm{w})$ \\
Asn172 ND2 to 0RN OAF & $3.2(\mathrm{~h})$ & $3.1(\mathrm{~h})$ \\
Glu168 O2 to 0RN OAF & $3.0(\mathrm{~h})$ & $2.8(\mathrm{~h})$ \\
Arg173 NH1 to ORN O & $2.5(\mathrm{~s})$ & $3.9(\mathrm{w})$ \\
Thr239 O to 0RN OAO & $3.9(\mathrm{w})$ & $2.9(\mathrm{~h})$ \\
\hline
\end{tabular}

(b) Distances in ( $\AA$ ) in subunits $B$ and $D$ to the Ser70 trans-enamine (TSS).

\begin{tabular}{lll}
\hline & Subunit $B$ & Subunit $D$ \\
\hline Lys73 NZ to TSS O13 & $2.8(\mathrm{~h})$ & $3.0(\mathrm{~h})$ \\
Gln109 OE1 to TSS O12 & Gln from $A, 2.7(\mathrm{~h})$ & Gln from $C, 2.9$ (h) \\
Thr239 O to TSS 08 & $2.9(\mathrm{~h})$ & $2.9(\mathrm{~h})$ \\
Asp241 OD2 to TSS O11 & 6.4 & 4.1 \\
\hline
\end{tabular}

(c) Distances in ( $\mathrm{A}$ ) during ceftriaxone binding (CEF is only bound to subunits $B$ and $D$ ).

\begin{tabular}{|c|c|c|c|c|c|c|c|c|}
\hline & \multicolumn{4}{|c|}{ Subunit $B$} & \multicolumn{4}{|c|}{ Subunit $D$} \\
\hline & $0 \mathrm{~ms}$ & $5 \mathrm{~ms}$ & $10 \mathrm{~ms}$ & $50 \mathrm{~ms}$ & $0 \mathrm{~ms}$ & $5 \mathrm{~ms}$ & $10 \mathrm{~ms}$ & $50 \mathrm{~ms}$ \\
\hline r70 OG to $\mathrm{H}_{2} \mathrm{C}$ & $1(\mathrm{~h})$ & $2.8(\mathrm{~h})$ & $3.3(\mathrm{w})$ & $2.8(\mathrm{~h})$ & $3.5(\mathrm{w})$ & $2.4 \dagger(\mathrm{s})$ & $3.1(\mathrm{~h})$ & $3.2(\mathrm{~h})$ \\
\hline Ser70 OG to $\mathrm{P}_{\mathrm{i}} \mathrm{O} 4$ & $3.6(\mathrm{w})$ & $3.5(\mathrm{w})$ & $3.4(\mathrm{w})$ & $2.6(\mathrm{~s})$ & $2.7(\mathrm{~h})$ & $3.7(\mathrm{w})$ & $3.9(\mathrm{w})$ & $2.7(\mathrm{~h})$ \\
\hline Ser70 OG to CEF O & nał & $3.1(\mathrm{~h})$ & $2.9(\mathrm{~h})$ & $2.9(\mathrm{~h})$ & na & $2.9(\mathrm{~h})$ & $3.0(\mathrm{~h})$ & $2.8(\mathrm{~h})$ \\
\hline Ser128 OG to CEF OAD & na & $2.4(\mathrm{~s})$ & $2.4(\mathrm{~s})$ & $2.5(\mathrm{~s})$ & na & $2.3(\mathrm{~s})$ & $2.4(\mathrm{~s})$ & $2.6(\mathrm{~h})$ \\
\hline Asn172 ND2 to CEF OAR & na & $2.7(\mathrm{~h})$ & $3.1(\mathrm{~h})$ & $3.2(\mathrm{~h})$ & na & $2.8(\mathrm{~h})$ & $3.0(\mathrm{~h})$ & $3.1(\mathrm{~h})$ \\
\hline Thr237 OG1 to & na & $2.7(\mathrm{~h})$ & $3.1(\mathrm{~h})$ & $3.0(\mathrm{~h})$ & na & 2.7 (h) & $2.6(\mathrm{~h})$ & $3.1(\mathrm{~h})$ \\
\hline Thr239 OG2 to CEF O & na & $3.3(\mathrm{w})$ & $3.0(\mathrm{~h})$ & $3.0(\mathrm{~h})$ & na & $3.4(\mathrm{w})$ & $3.4(\mathrm{w})$ & $3.1(\mathrm{~h})$ \\
\hline Asp241 OD1 to CEF NAC & na & 4.7 & 4.3 & $3.2(h)$ & na & 4.4 & 4.2 & $3.6(w)$ \\
\hline
\end{tabular}

$\dagger$ Weak OMIT difference electron density. $\ddagger$ Not applicable.

2003; Kostov \& Moffat, 2011). The high X-ray pulse-repetition rate of the EuXFEL may make this possible since it allows the fast collection of data sets at tightly spaced delays. Given the resolution of our X-ray data (Table 1 ), it is challenging to make a distinction between ligand binding being supported by conformational disorder (Tzeng \& Kalodimos, 2012) or by adaptation of the structure to a changing energy landscape, which would resemble an 'induced fit' (Changeux \& Edelstein, 2011). Both scenarios (Vogt \& Di Cera, 2012) would most likely result in the same (or a very similar) crystallographic signal. We hypothesize that both mechanisms are involved to some degree, which might be unraveled by single-particle experiments, as recently demonstrated for an unrelated biological system (Dashti et al., 2020). However, the structures of BlaC as well as of CEF change [Table 4(c), Supplementary Movie S1], which might be interpreted as the signature of an induced fit after the initial binding event.

Formation of the ES complex is most important since it triggers the enzymatic cycle. Hence, it determines the time resolution of the MISC method. The ES complex consists of CEF noncovalently bound in the active site of BlaC (Fig. 4). $\mathrm{CEF}$ is delivered by diffusion into the crystals. The crystals must be small enough to enable short enough diffusion times so that the binding kinetics can be observed. However, MISC does not measure the free substrate concentration in the crystals, and therefore diffusion is rather observed indirectly through the increase in the occupancies of well ordered substrate molecules in the active centers of BlaC. When the diffusion times are very short, occupancies may accumulate on a timescale longer than the diffusion time, as they are governed by the binding kinetics. The formation of the ES complex, and therefore the time resolution of the MISC method, is therefore not only dependent on the ligand concentration delivered by diffusion but also on the magnitude of the rate coefficients that characterize the kinetic mechanism.

\subsection{Inhibitor binding}

The structure of the BlaC-SUB complex was probed at $\Delta t_{\mathrm{m}}=66 \mathrm{~ms}$. Strong positive $\mathrm{DED}_{\text {iso }}$ shows SUB binding to all four subunits of BlaC, which is in stark contrast to CEF, which only binds to subunits $B$ and $D$. The absence of negative $\mathrm{DED}_{\text {iso }}$ at the $\mathrm{P}_{\mathrm{i}}$ position [Figs. 7( $a)$ and 7(b)] shows that the $\mathrm{P}_{\mathrm{i}}$ does not move and stays in the active site. At the time delay of $66 \mathrm{~ms}$ sulbactam binding to BlaC is heterogeneous. In subunits $B$ and $D$ the $\mathrm{DED}_{\text {iso }}$ is elongated and stretches outwards from Ser70 [Fig. 7(b)]. In subunits $A$ and $C$ the $\mathrm{DED}_{\text {iso }}$ is pillow-like and is more distant from Ser70 [Fig. 7(a)]. The elongated $\mathrm{DED}_{\text {iso }}$ in subunits $B$ and $D$ [Fig. 7(b)] can be explained by a covalently bound trans-EN as a result of the reaction of the sulbactam with the catalytic Ser70. The diffusion time is fast enough that 66 ms after mixing all $B$ and $D$ subunits contain trans-EN, the position of which is stabilized by a network of BlaC residues [Fig. 7 and Table 4(b)]. This is quite unexpected, as it was suggested that it would take minutes for the enamine to form after binding of SUB to BlaC (Totir et al., 2007; Cheng et al., 2020; Tassoni et al., 2019). In subunits $B$ and $D$ Arg173 displays a stretched, open conformation, allowing the SUB to orient correctly towards Ser70 and to react swiftly to the trans-EN, which then irreversibly inhibits BlaC (Tassoni et al., 2019). The nearby $\mathrm{P}_{\mathrm{i}}$, which is displaced when the much larger ligand CEF is present, stays in place in all subunits and is likely to add to the stability of both complexes.

The pillow-like $\mathrm{DED}_{\text {iso }}$ in a region more distant from Ser70 in subunits $A$ and $C$ [Fig. 7(a)] can be explained by an intact sulbactam molecule that is noncovalently bound to the active site. The SUB is oriented so that the ring sulfur dioxide points towards Ser70, with the $\beta$-lactam ring pointing away from Ser70. We hypothesize that this 'upside-down' orientation is 
enforced by $\operatorname{Arg} 173$ and Gln112 [Fig. 7(a) and Table 4(a)], where Gln112 protrudes deep into the active sites from the adjacent, noncrystallographically related subunits [Fig. 7(a)]. As the noncovalently bound SUB is oriented incorrectly, Ser70 cannot attack and open the $\beta$-lactam ring within the $\Delta t_{\mathrm{m}}$ of $66 \mathrm{~ms}$. However, the static (cryo) X-ray structure of this complex [Fig. 5(c)] shows that SUB indeed also reacts to the trans-EN in subunits $A$ and $C$. Accordingly, the BlaC-SUB structure is an interesting intermediate on the catalytic pathway from SUB to trans-EN. The detection of this intermediate would be difficult if not impossible without the MISC experiment.

\subsection{Diffusion of substrate in BlaC microcrystals}

With $D=2.3 \times 10^{-6} \mathrm{~cm}^{2} \mathrm{~s}^{-1}$ for CEF in water [Table 5(b)], the diffusion time into the center of a $10 \times 10 \times 2 \mu \mathrm{m}$ crystal volume consisting of water is $1.6 \mathrm{~ms}$. This means that at $5 \mathrm{~ms}$ the concentration of CEF molecules would be $96 \%$ of the outside concentration (about $144 \mathrm{mM}$ ), which is about 20 times higher than the stoichiometric concentration [Table 5(a)]. After integration of the rate equation, the



(a)



(b)

Figure 7

BlaC-SUB complexes at $\Delta t_{\mathrm{m}}=66 \mathrm{~ms}$. (a) Active site in subunit $C$ with noncovalently bound intact sulbactam; left side, $\mathrm{DED}_{\text {iso }}$ map (contour: $3 \sigma$ ); right side, $2 m F_{\mathrm{o}}-D F_{\mathrm{c}}$ map (contour: $1.7 \sigma$ ) after refinement. Closeby amino acids and the phosphate $\left(\mathrm{P}_{\mathrm{i}}\right)$ are marked. $(b)$ Active site in subunit $B$ with trans-enamine bound to Ser70; left side, $\mathrm{DED}_{\text {iso }}$ map (contour: $3 \sigma$ ); right side, $2 m F_{\mathrm{o}}-D F_{\mathrm{c}}$ map (contour: $1.7 \sigma$ ) after refinement. Red and blue dots show important differences between the subunits. Gln112 from the adjacent subunit is not located close by and $\operatorname{Arg} 173$ is extended in subunit $B$, leaving subunit $B$ more accessible to ligands and substrate.
Table 5

Characterization of BlaC-CEF complex formation in crystals.

(a) Parameters for the binding of CEF to BlaC [see also Fig. 3 and equation (4)]. The concentration $E_{0}$ of all subunits in the BlaC platelet crystal form is $15.5 \mathrm{~m} M$. Only subunits $B$ and $D$ bind substrate. $C_{0, \mathrm{CEF}}$ is the mixed-in substrate concentration [see equation (3)].

\begin{tabular}{lll}
\hline$E_{0}(\mathrm{~m} M)$ & $C_{0, \mathrm{CEF}}(\mathrm{m} M)$ & $k_{\mathrm{on}}\left(M^{-1} \mathrm{~s}^{-1}\right)$ \\
\hline 7.8 & 150 & 3.2
\end{tabular}

(b) Parameters in equations (1)-(5) that were fitted to the respective refined occupancy values of CEF and $\mathrm{P}_{\mathrm{i}}$. The comparison of observed and calculated occupancies allows the determination of a diffusion coefficient $D_{\text {eff. }}$.

\begin{tabular}{|c|c|c|c|c|c|c|}
\hline \multirow{2}{*}{\multicolumn{2}{|c|}{$\begin{array}{l}\begin{array}{l}\text { BlaC-CEF } \\
\text { increase, (1) }\end{array} \\
\text { Observed } \dagger\end{array}$}} & \multirow{3}{*}{$\begin{array}{l}P_{\mathrm{i}} \text { decrease, } \\
(2) \\
\text { Observed } \dagger\end{array}$} & \multicolumn{2}{|c|}{$\begin{array}{l}\text { BlaC-CEF in the } \\
\text { crystal center, (5) }\end{array}$} & \multirow{2}{*}{\multicolumn{2}{|c|}{$\begin{array}{l}D\left(\mathrm{~cm}^{2} \mathrm{~s}^{-1}\right) \text { for } \mathrm{CEF}, \\
\text { (3) and (4) }\end{array}$}} \\
\hline & & & \multicolumn{2}{|c|}{ Sigmoidal increase } & & \\
\hline $\mathrm{S}, \mathrm{CEF}$ & $\overline{\tau_{1 / 2}(\mathrm{~ms})}$ & & $k\left(\mathrm{~ms}^{-1}\right)$ & & Nater & $D_{8}$ \\
\hline$\%$ & 4.6 & 6.7 & 0.5 & 13.1 & $2.3 \times 10^{-6}$ & $2 \times 10^{-7}$ \\
\hline
\end{tabular}

(c) Calculated occupancies which could be determined with the help of $D_{\text {eff. }}$ The free CEF, free BlaC ([ $\left.\left.\mathrm{E}_{\text {free }}\right]\right)$ and BlaC-CEF complex ([ES]) concentrations were averaged (angle brackets) over all voxels in the crystal. $\left[\mathrm{ES}_{\mathrm{center}}\right]$ is the BlaC-CEF complex concentration in the center of the microcrystal platelets. Values in parentheses either denote the inside CEF concentration in terms of the percentage of the outside CEF concentration or represent the occupancy values of the relevant species.

\begin{tabular}{lllll}
\hline$\Delta t_{\mathrm{m}}(\mathrm{ms})$ & $\langle[\mathrm{CEF}]\rangle(\mathrm{m} M)$ & $\left\langle\left[\mathrm{E}_{\text {free }}\right]\right\rangle(\mathrm{m} M)$ & $\langle[\mathrm{ES}]\rangle(\mathrm{m} M)$ & {$\left[\mathrm{ES}_{\text {center }}\right](\mathrm{m} M)$} \\
\hline 5 & $79.4(53 \%)$ & $3.9(50 \%)$ & $3.9(50 \%)$ & $0.2(2.7 \%)$ \\
10 & $98.4(66 \%)$ & $1.7(21 \%)$ & $6.1(79 \%)$ & $2.4(30 \%)$ \\
30 & $133.3(89 \%)$ & $0.0(0.1 \%)$ & $7.8(99.9 \%)$ & $7.7(99 \%)$ \\
50 & $144.4(96 \%)$ & $0.0(0 \%)$ & $7.8(100 \%)$ & $7.8(100 \%)$ \\
\hline
\end{tabular}

$\dagger$ From fitting saturation curves to refined occupancy values. $C_{\mathrm{S} \text {.CEF }}$ is the saturation concentration of CEF; $\tau_{12}$ are characteristic times where $50 \%$ of the final concentrations of CEF and phosphate are reached, respectively. $\ddagger$ Parameters of the logistics function (5) fitted to occupancies determined in the centers of the BlaC platelets. $\& D_{\text {eff }}$ was obtained by matching the calculated and observed CEF binding kinetics.

average occupancy would be $99 \%$, which is essentially saturation. This result does not reflect the crystallographically observed occupancy at $5 \mathrm{~ms}$. When decreasing the diffusion coefficient to $2.0 \times 10^{-7} \mathrm{~cm}^{2} \mathrm{~s}^{-1}$, the diffusion time into the crystal center increases to $19 \mathrm{~ms}$ [see Fig. 6(b) and Table 5(b)]. From this, the decrease of the free BlaC enzyme concentration, the increase of the free CEF concentration and the increase of the BlaC-CEF complex concentration were calculated as explained in Section 2.5. The results are shown in Fig. 6(b). The BlaC-CEF concentration in the center of the crystal lags behind [blue diamonds in Fig. 6(b)] since CEF requires additional time to reach the center and to bind to $\mathrm{BlaC}$. The resulting sigmoidal-shaped response was fitted by a logistic function,

$$
[\mathrm{ES}]_{\mathrm{center}}=\frac{100}{1+\exp \left[-k\left(t-t_{0}\right)\right]},
$$

where $t_{0}=13.1 \mathrm{~ms}$ denotes the characteristic time when the binding reaction accelerates in the crystal center. With $k=$ $0.3 \mathrm{~ms}^{-1}$ a reasonable steepness of (5) was achieved [Fig. 6(b), blue dashed line]. The $t_{0}$ roughly coincides with the diffusion time. Averaged over the entire crystal volume, $\sim 50 \%$ BlaCCEF occupancy is reached at $5 \mathrm{~ms}$, which is equal to the 


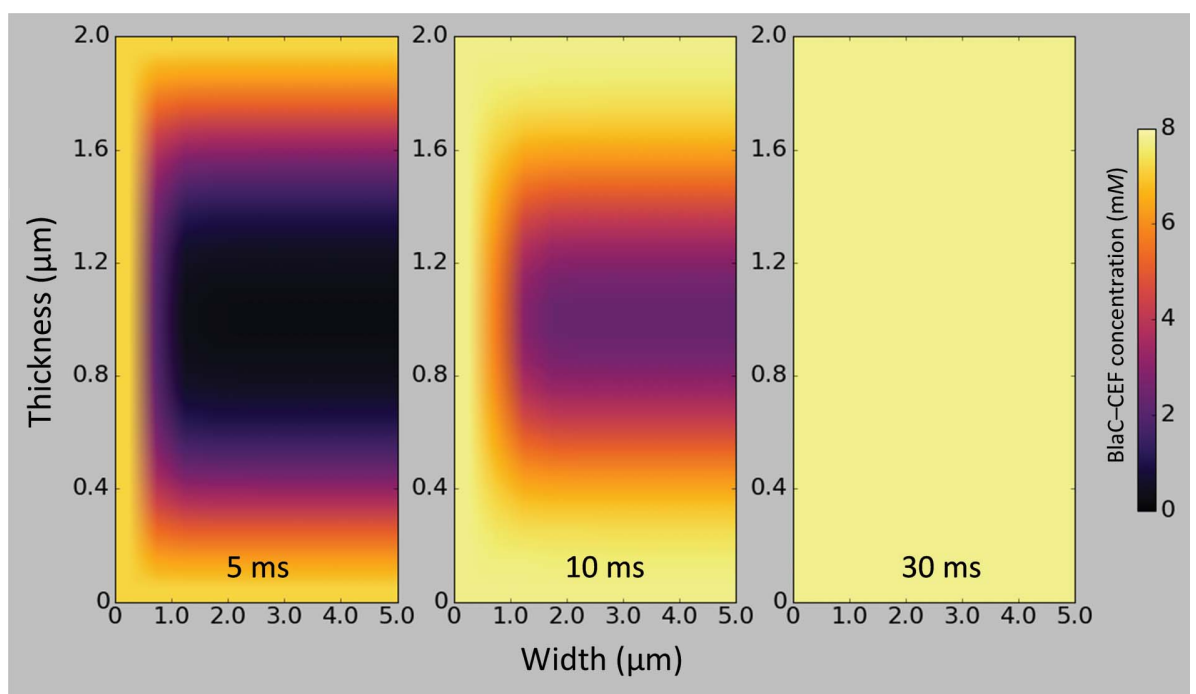

Figure 8

Concentrations of the BlaC-CEF complex in $10 \times 10 \times 2 \mu \mathrm{m}$ platelet-shaped crystals $(a) 5 \mathrm{~ms},(b)$ $10 \mathrm{~ms}$ and $(c) 30 \mathrm{~ms}$ after mixing with $200 \mathrm{~m} M$ ceftriaxone ( $150 \mathrm{~m} M$ final concentration assumed). The concentrations are shown in different colors (see the scale bar on the right) in central cross sections through half the width of the crystals. The drawings are not to scale, since the sections displayed are $5 \mu \mathrm{m}$ horizontally (width) and $2 \mu \mathrm{m}$ vertically (thickness). The enlargement along the short $2 \mu \mathrm{m}$ axis allows the display of the nuanced occupancy differences.

occupancy determined experimentally at $\Delta t_{\mathrm{m}}=5 \mathrm{~ms}$ [compare the green dashed line in Fig. 6(b) with Fig. 6(a)]. Fig. 8 shows a heatmap that plots BlaC-CEF occupancies through the center of half a BlaC crystal (see also Fig. 9 for a 3D representation). The concentrations of the BlaC-CEF complex are depicted with various colors (see the scale bar on the right). At the edge of the crystal, almost all active $\mathrm{BlaC}$ subunits $(B$ and $D)$ are already bound to $\mathrm{CEF}$ at $5 \mathrm{~ms}$. In the center the $\mathrm{BlaC}-\mathrm{CEF}$ complex concentration is $0.21 \mathrm{~m} M(2.7 \%$ of the total concentration of $B$ and $D$ subunits in the crystal), although the CEF concentration delivered by diffusion is already $35 \mathrm{mM}$ (which is the mentioned $23 \%$ of the outside CEF concentration but is 5.5 times the stoichiometric concentration). The situation changes completely at $30 \mathrm{~ms}$, where almost $100 \%$ occupancy is reached everywhere in the crystal, which is in accordance with earlier results (Olmos et al., 2018) and with the occupancy at $\Delta t_{\mathrm{m}}=50 \mathrm{~ms}$ reported here (see also



(a)

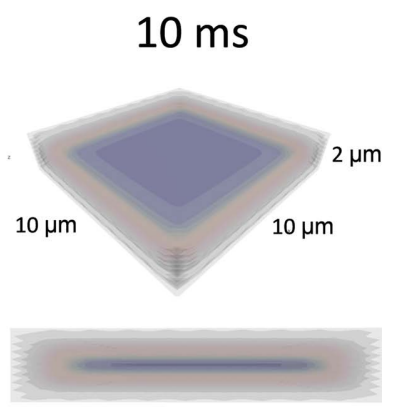

(b)
Figure 9

3D representation of CEF occupancy values in the BlaC catalytic cleft $5 \mathrm{~ms}(a)$ and $10 \mathrm{~ms}(b)$ after mixing in a typical BlaC microcrystal platelet. Dark blue colors denote low occupancies and lighter hues denote high occupancies.
Supplementary Movie S2). As also discussed earlier, the variation of occupancy across microcrystals at faster mixand-inject delays does not affect the enzyme kinetics, as the nucleophilic attack of Ser70 of BlaC on the $\beta$-lactam ring happens long after the crystals establish full CEF occupancy. It needs to be pointed out here that the simple model of CEF diffusion into BlaC microcrystals and the binding of CEF to BlaC molecules can be augmented by taking into account, for example, the exclusion volume occupied by reacting and nonreacting BlaC subunits (Geremia et al., 2006), by the mentioned pointwise depletion of the free CEF concentration in each voxel by binding to $\mathrm{BlaC}$ active centers, or the diffusion of substrate directly through protein molecules facilitated by protein dynamics. Since the exact mechanism of diffusion through protein crystals (Geremia et al., 2006) is difficult to determine, the unknown parameters are tied up in the effective diffusion coefficient $\left(D_{\text {eff }}\right)$ determined here.

\subsection{Reaction initiation by diffusion}

CEF diffusion is about a factor of 12 slower in the $\mathrm{BlaC}$ crystals than in water, with a $D_{\text {eff }}$ of about $\sim 2 \times 10^{-7} \mathrm{~cm}^{2} \mathrm{~s}^{-1}$ [Table 5(b)]. This slowdown is in agreement with findings that were previously obtained from simulations on substrate diffusion in enzyme crystals (Geremia et al., 2006). Estimates of enzyme-ligand occupancies can now be directly deduced from time-resolved X-ray crystallography everywhere in a crystal after mixing. Not surprisingly, at $5 \mathrm{~ms}$ the occupancy is high $(>90 \%)$ only near the crystal surface [Fig. $8(a)$ ], where sufficient substrate is present to promote ES formation at a high rate. In the center of the crystals the ES complex concentration is initially small [Table 5(c), Figs. 8(a) and $9(a)$ ]. The binding rate is not sufficiently high to generate significant occupancy. After $\Delta t_{\mathrm{m}}=10 \mathrm{~ms}$ the binding rate increases, until at $30 \mathrm{~ms}$ full occupancy of the BlaC-CEF complex is reached everywhere (Olmos et al., 2018) [Fig. 6(b), green dashed line, Table 5(c)]. With the rapid diffusion of CEF into small BlaC crystals, we are now able to quantify variations of substrate, enzyme and ES concentrations across the enzyme crystal volume at any time [Table 5(c), Figs. 8 and 9]. The remarkable speed of ES accumulation shows that the mix-and-inject technique can be used to characterize enzymes with turnover times much faster than that of BlaC. The direct observation of the important initial ligand- and substrate-binding phase in biomedically relevant enzymes is possible at the EuXFEL.

Since the ES complex (here the BlaC-CEF complex) triggers the enzymatic cycle, accurate kinetics can be extracted to the point where the time required to accumulate sufficient ES 
complex approaches the lifetime of the next intermediate in the catalytic cycle (Schmidt, 2013). This finding holds for any other technique (Šrajer \& Schmidt, 2017) which aims to trigger enzymatic reactions, even in noncrystalline samples. Not only is it required to bring sufficient substrate into the vicinity of the enzyme, but the binding kinetics also need to be taken into account. With microcrystals below a certain crystal size, the binding of substrate, and not the diffusion of substrate into the crystal volume, may become rate-limiting. As a consequence, for $\mathrm{BlaC}$ crystals of a size of about $1 \mu \mathrm{m}$ the speed of ES complex formation is not substantially different from that in solution. The $D_{\text {eff }}$ determined here suggests that accurate measurements of the substrate-binding kinetics would not be possible with significantly larger crystals. Enzymes with turnover times faster than that of $\mathrm{BlaC}$ will usually also display faster substrate-binding kinetics with larger $k_{\text {on }}$ rate coefficients. In such cases, the crystal sizes (and their size distributions) or perhaps the temperature must be adjusted appropriately to ensure that the diffusion times can catch up with the substrate-binding rates.

Diffusion is an effective way to initiate reactions. Given a sufficient substrate concentration, and appropriately small crystals, all of the crystal volume is already infused with a multiple of the stoichiometric substrate concentration after a few milliseconds [Table 5(c)]. This is very important for fast reaction initiation since the rate (speed) of enzyme-substrate complex formation, and therefore the time resolution of the method, depends decisively, and primarily, on the concentration of the substrate, and of course also on the free enzyme concentration and the kinetic rate coefficients. Others (Mehrabi, Schulz, Dsouza et al., 2019) have reported significant substrate occupancy in the active site only $30 \mathrm{~ms}$ after the activation of a caged substrate that is even located close by. This slow occupancy increase may be a result of (sub-)stoichiometric substrate concentrations in the unit cell, which strengthens our point of view. $\mathrm{BlaC}$ is not a fast enzyme. Apart from the possibility of investigating the initial substrate- binding phase(s) potentially on submillisecond timescales, the benefits of XFEL-based mix-and-inject approaches may come to light once faster enzymes with turnover times of $<50 \mathrm{~ms}$ are investigated. These experiments require small crystals. Exploration of how to investigate these small crystals using either XFELs or synchrotrons, perhaps after upgrade to an advanced accelerator lattice (Eriksson, 2016; Wanzenberg $e t$ al., 2019), remains to be performed.

\section{Outlook}

In order to further investigate CEF and SUB binding and their reactions with Ser70, a time series should be collected that consists of data sets at multiple $\Delta t_{\mathrm{m}}$ values that span from a few milliseconds to seconds. To achieve this, the EuXFEL pulse structure must be exploited most efficiently. Every X-ray pulse in all pulse trains provides observations of the same time delay, and our experiments took maximum advantage of the high pulse rate (Fig. 2, inset). This is in contrast to optical pump-X-ray probe experiments, which require appropriate waiting times between laser excitations to guarantee that the laser-excited volume exits the $\mathrm{X}$-ray interaction region, so that multiple laser activations can be avoided (Pandey et al., 2020). We showed that diffraction data sufficient for good-quality structure determination can be collected in about half an hour, as demonstrated for the $50 \mathrm{~ms}$ CEF time point. This time can be reduced substantially by limiting the number of diffraction patterns per data set (around 25000 is appropriate for this space group; Olmos et al., 2018) and by optimizing the crystal density that flows through the mixing device. High crystal density will lead to higher hit rates, but might also cause frequent interruptions caused by injector clogging. In our experiments, a fine balance between crystal size and crystal density was found so that the mix-and-inject experiments with CEF and SUB could be completed successfully with acceptable hit rates (Table 1) given the high X-ray pulse-repetition rate at the EuXFEL. Previous experiments have shown that

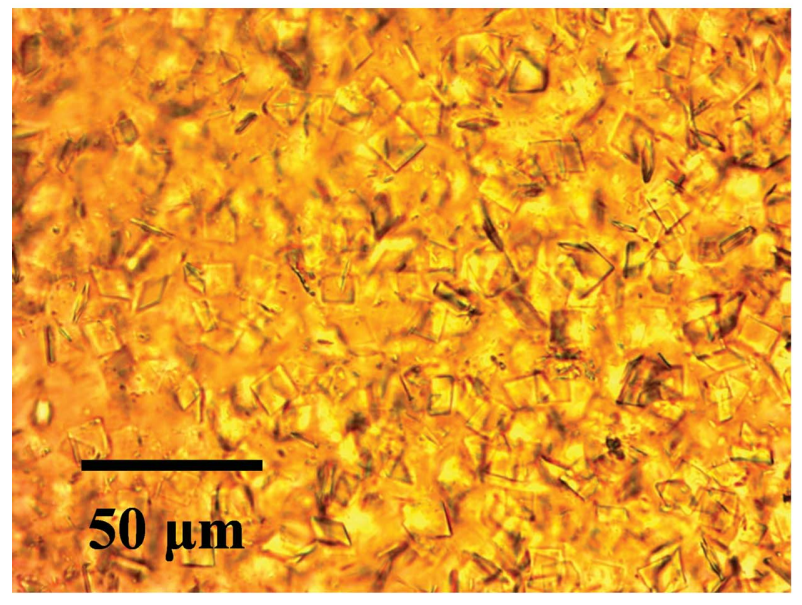

(a)

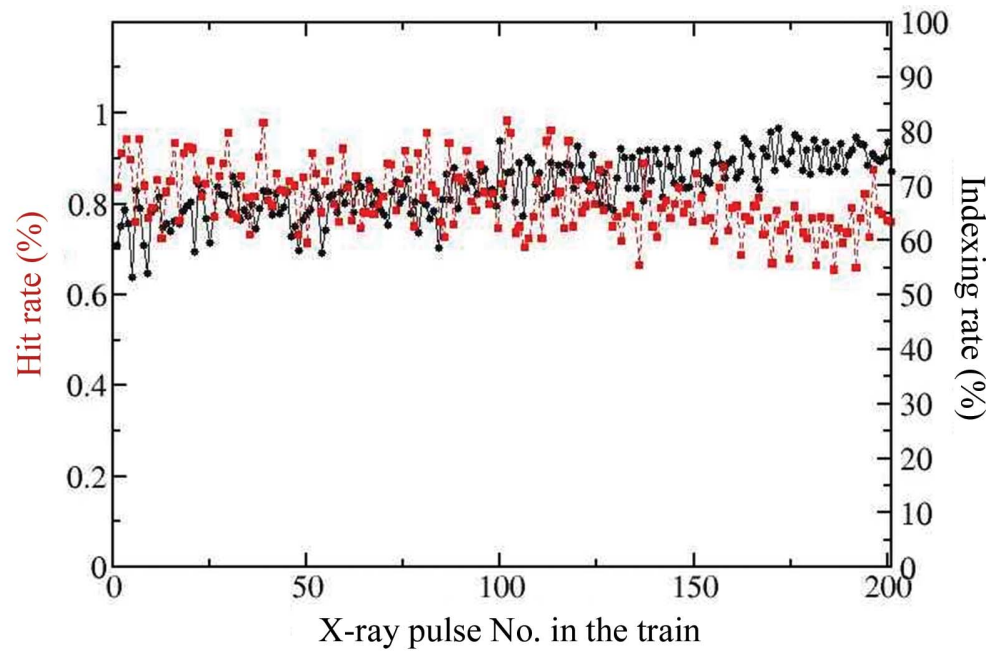

(b)

Figure 10

Crystals, hit and indexing rates. (a) Microscopic image of the platelet crystal form of BlaC and (b) exemplary hit (red squares) and indexing (black spheres) rates from BlaC/CEF mixing as a function of the pulse ID in the train. Both rates are stable across the entire pulse train. 
the collection of sufficient patterns for structure determination should be possible in less than $20 \mathrm{~min}$ at the detector-limited repetition rate of the EuXFEL (Yefanov et al., 2019; Pandey et $a l ., 2020)$. This provides the tantalizing possibility of directly characterizing kinetic processes in biomolecules from singledigit millisecond to longer timescales within relatively short experimental times. The kinetics can rapidly change when environmental conditions are varied. It may be possible, for example, to control the temperature in the mixing injector delay line to determine barriers of activation from the resulting X-ray data (Schmidt et al., 2013). The full analysis of such a multidimensional data set requires the development and deployment of user-friendly classification algorithms to separate mixtures into their pure components (Schmidt et al., 2003) and to derive kinetics and energetics (Schmidt et al., 2013) consistent with the electron-density maps and the structures of intermediate states along the reaction pathway.

\section{Summary}

Our experiments permitted a real-time view into the active sites of an enzyme during substrate binding. They facilitate more mix-and-inject experiments at the EuXFEL with unprecedented data-collection rates, allowing more structures to be determined per allocated experimental time. This capability will become an important tool for biomedically relevant research in years to come.



Figure 11

(a)

\section{APPENDIX $A$}

\section{Microcrystals and data collection}

Fig. 10(a) shows a microscopic image of the BlaC platelets used for the experiments. They appear to be uniform in size and shape. In Fig. 10(b) the hit and indexing rates achieved with these crystals in our MISC experiments are displayed across all of the pulses in the pulse train of the EuXFEL. A decay in the hit rate following pulse 1 is not observed. This is an indication that the jet is fast enough that a fresh jet volume is intercepted by the following X-ray pulses (Wiedorn, Oberthür et al., 2018; Yefanov et al., 2019; Pandey et al., 2020).

\section{APPENDIX $B$ \\ Diffraction patterns and masks}

The ability to mask out detector pixels and other parts of the diffraction pattern (Fig. 11) is important for the successful identification of DP-containing Bragg reflections (hits) from the stream of detector images (Wiedorn, Oberthür et al., 2018; Carrillo et al., 2021). Only peaks [blue squares in Figs. 11(a) and 11(b)] outside the mask are found. In the hit-finder Cheetah (Barty et al., 2014) a convenient masking tool is available that facilitates the exclusion of any part of the detector image. The central 'hole' and the gaps (except for the tile edges) do not need to be masked since the detector geometry is known.



(b)

(a) Example of a diffraction pattern collected by the AGIPD. In (b) a mask (in red) is superposed that covers the strong rings at low resolution and inactive detector areas. 


\section{Acknowledgements}

We are very grateful to those who supported this experiment by being present in person at the European XFEL during the onset of the COVID-19 pandemic in March 2020. We acknowledge the European XFEL in Schenefeld, Germany for the provision of X-ray free-electron laser beamtime on the SPB/SFX scientific instrument and would like to thank the staff for their assistance. We acknowledge the use of the XBI facility at the European XFEL. The SFX stream files were deposited in the CXIDB with code 170. Individual contributions were as follows. SP, TM, JM-G, JH-Y, FK, IP, MM, RJ, MS, WX and JO expressed, purified and crystallized the protein. RB, KD, HK, MK, JK, GM, TS and MV operated the SPB/SFX instrument. LP, AMK, GC and KAZ designed and provided injector nozzles. MV, FK and MK assembled and operated the nozzles. FK, JM-G, J-HY, LG and PS collected the data. SP, IP, OY, VM, PS, AT and AB processed the data. SP, IP, TM, GP and MS analyzed the data. IP, MF, AS, FK, PS and MS logged the experiment. RB, APM, MS and GP designed the experiment. SP, PF, APM, RB, GP and MS wrote the manuscript with input from all other authors.

\section{Funding information}

This work was supported by the National Science Foundation Science and Technology Center 'BioXFEL' through award STC-1231306, and in part by the US Department of Energy, Office of Science, Basic Energy Sciences under contract DESC0002164 (AO, algorithm design and development) and by the National Science Foundation under contract Nos. 1551489 (AO, underlying analytical models) and DBI-2029533 (AO, functional conformations). This material is based upon work supported by the National Science Foundation Graduate Research Fellowship Program under Grant No. 1450681 to JLO. The work was also supported by funds from the National Institutes of Health grant R01 GM117342-0404. Funding and support are also acknowledged from the National Institutes of Health grant R01 GM095583, from the Biodesign Center for Applied Structural Discovery at ASU, from National Science Foundation award No. 1565180 and the US Department of Energy through Lawrence Livermore National Laboratory under contract DE-AC52-07NA27344. KAZ was supported by the Cornell Molecular Biophysics Training Program (NIH T32-GM008267). This work was also supported by the Cluster of Excellence 'CUI: Advanced Imaging of Matter' of the Deutsche Forschungsgemeinschaft (DFG), EXC 2056, project ID 390715994. CFEL is supported by the Gottfried Wilhelm Leibniz Program of the DFG, the 'X-probe' project funded by the European Union 2020 Research and Innovation Program under Marie Sklodowska-Curie grant agreement 637295, the European Research Council, 'Frontiers in Attosecond X-ray Science: Imaging and Spectroscopy (AXSIS)', ERC-2013-SyG 609920, and the Human Frontiers Science Program grant RGP0010 2017. This work is also supported by the AXSIS project funded by the European Research Council under the European Union Seventh Framework Program (FP/20072013)/ERC Grant Agreement No. 609920.

\section{References}

Allahgholi, A., Becker, J., Delfs, A., Dinapoli, R., Goettlicher, P., Greiffenberg, D., Henrich, B., Hirsemann, H., Kuhn, M., Klanner, R., Klyuev, A., Krueger, H., Lange, S., Laurus, T., Marras, A., Mezza, D., Mozzanica, A., Niemann, M., Poehlsen, J., Schwandt, J., Sheviakov, I., Shi, X., Smoljanin, S., Steffen, L., Sztuk-Dambietz, J., Trunk, U., Xia, Q., Zeribi, M., Zhang, J., Zimmer, M., Schmitt, B. \& Graafsma, H. (2019). J. Synchrotron Rad. 26, 74-82.

Barends, T. R. M., Foucar, L., Ardevol, A., Nass, K., Aquila, A., Botha, S., Doak, R. B., Falahati, K., Hartmann, E., Hilpert, M., Heinz, M., Hoffmann, M. C., Kofinger, J., Koglin, J. E., Kovacsova, G., Liang, M., Milathianaki, D., Lemke, H. T., Reinstein, J., Roome, C. M., Shoeman, R. L., Williams, G. J., Burghardt, I., Hummer, G., Boutet, S. \& Schlichting, I. (2015). Science, 350, 445-450.

Barty, A., Kirian, R. A., Maia, F. R. N. C., Hantke, M., Yoon, C. H., White, T. A. \& Chapman, H. (2014). J. Appl. Cryst. 47, 1118-1131.

Berman, H. M., Battistuz, T., Bhat, T. N., Bluhm, W. F., Bourne, P. E., Burkhardt, K., Feng, Z., Gilliland, G. L., Iype, L., Jain, S., Fagan, P., Marvin, J., Padilla, D., Ravichandran, V., Schneider, B., Thanki, N., Weissig, H., Westbrook, J. D. \& Zardecki, C. (2002). Acta Cryst. D58, 899-907.

Boutet, S., Lomb, L., Williams, G. J., Barends, T. R., Aquila, A., Doak, R. B., Weierstall, U., DePonte, D. P., Steinbrener, J., Shoeman, R. L., Messerschmidt, M., Barty, A., White, T. A., Kassemeyer, S., Kirian, R. A., Seibert, M. M., Montanez, P. A., Kenney, C., Herbst, R., Hart, P., Pines, J., Haller, G., Gruner, S. M., Philipp, H. T., Tate, M. W., Hromalik, M., Koerner, L. J., van Bakel, N., Morse, J., Ghonsalves, W., Arnlund, D., Bogan, M. J., Caleman, C., Fromme, R., Hampton, C. Y., Hunter, M. S., Johansson, L. C., Katona, G., Kupitz, C., Liang, M., Martin, A. V., Nass, K., Redecke, L., Stellato, F., Timneanu, N., Wang, D., Zatsepin, N. A., Schafer, D., Defever, J., Neutze, R., Fromme, P., Spence, J. C. H., Chapman, H. N. \& Schlichting, I. (2012). Science, 337, 362-364.

Boyd, D. B. \& Lunn, W. H. (1979). J. Med. Chem. 22, 778-784.

Calvey, G. D., Katz, A. M. \& Pollack, L. (2019). Anal. Chem. 91, 71397144.

Carrillo, M., Pandey, S., Sanchez, J., Noda, M., Poudyal, I., Aldama, L., Malla, T. N., Claesson, E., Wahlgren, W. Y., Feliz, D., Srajer, V., Maj, M., Castillon, L., Iwata, S., Nango, E., Tanaka, R., Tanaka, T., Fangjia, L., Tono, K., Owada, S., Westenhoff, S., Stojković, E. A. \& Schmidt, M. (2021). Structure, 29, 743-754.

Carslaw, H. S. \& Jaeger, J. C. (1959). Conduction Heat in Solids, 2nd ed. Oxford: Clarendon Press.

Cassini, A., Högberg, L. D., Plachouras, D., Quattrocchi, A., Hoxha, A., Simonsen, G. S., Colomb-Cotinat, M., Kretzschmar, M. E., Devleesschauwer, B., Cecchini, M., Ouakrim, D. A., Oliveira, T. C., Struelens, M. J., Suetens, C., Monnet, D. L., Strauss, R., Mertens, K., Struyf, T., Catry, B., Latour, K., Ivanov, I. N., Dobreva, E. G., Tambic-Andraševic, A., Soprek, S., Budimir, A., Paphitou, N., Žemlicková, H., Schytte Olsen, S., Wolff Sönksen, U., Märtin, P., Ivanova, M., Lyytikäinen, O., Jalava, J., Coignard, B., Eckmanns, T., Abu Sin, M., Haller, S., Daikos, G. L., Gikas, A., Tsiodras, S., Kontopidou, F., Tóth, Á., Hajdu, Á., Guólaugsson, Ó., Kristinsson, K. G., Murchan, S., Burns, K., Pezzotti, P., Gagliotti, C., Dumpis, U., Liuimiene, A., Perrin, M., Borg, M. A., de Greeff, S. C., Monen, J. C., Koek, M. B., Elstrøm, P., Zabicka, D., Deptula, A., Hryniewicz, W., Caniça, M., Nogueira, P. J., Fernandes, P. A., Manageiro, V., Popescu, G. A., Serban, R. I., Schréterová, E., Litvová, S., Štefkovicová, M., Kolman, J., Klavs, I., Korošec, A., Aracil, B., Asensio, A., Pérez-Vázquez, M., Billström, H., Larsson, S., Reilly, J. S., Johnson, A. \& Hopkins, S. (2019). Lancet Infect. Dis. 19, 56-66.

Changeux, J.-P. \& Edelstein, S. (2011). F1000 Biol. Rep. 3, 19.

Chapman, H. N., Fromme, P., Barty, A., White, T. A., Kirian, R. A., Aquila, A., Hunter, M. S., Schulz, J., DePonte, D. P., Weierstall, U., Doak, R. B., Maia, F. R. N. C., Martin, A. V., Schlichting, I., Lomb, L., Coppola, N., Shoeman, R. L., Epp, S. W., Hartmann, R., Rolles, 
D., Rudenko, A., Foucar, L., Kimmel, N., Weidenspointner, G., Holl, P., Liang, M., Barthelmess, M., Caleman, C., Boutet, S., Bogan, M. J., Krzywinski, J., Bostedt, C., Bajt, S., Gumprecht, L., Rudek, B., Erk, B., Schmidt, C., Hömke, A., Reich, C., Pietschner, D., Strüder, L., Hauser, G., Gorke, H., Ullrich, J., Herrmann, S., Schaller, G., Schopper, F., Soltau, H., Kühnel, K.-U., Messerschmidt, M., Bozek, J. D., Hau-Riege, S. P., Frank, M., Hampton, C. Y., Sierra, R. G., Starodub, D., Williams, G. J., Hajdu, J., Timneanu, N., Seibert, M. M., Andreasson, J., Rocker, A., Jönsson, O., Svenda, M., Stern, S., Nass, K., Andritschke, R., Schröter, C.-D., Krasniqi, F., Bott, M., Schmidt, K. E., Wang, X., Grotjohann, I., Holton, J. M., Barends, T. R. M., Neutze, R., Marchesini, S., Fromme, R., Schorb, S., Rupp, D., Adolph, M., Gorkhover, T., Andersson, I., Hirsemann, H., Potdevin, G., Graafsma, H., Nilsson, B. \& Spence, J. C. H. (2011). Nature, 470, 73-77.

Cheng, Q., Xu, C., Chai, J., Zhang, R., Wai Chi Chan, E. \& Chen, S. (2020). ACS Infect. Dis. 6, 577-587.

Coquelle, N., Sliwa, M., Woodhouse, J., Schirò, G., Adam, V., Aquila, A., Barends, T. R. M., Boutet, S., Byrdin, M., Carbajo, S., De la Mora, E., Doak, R. B., Feliks, M., Fieschi, F., Foucar, L., Guillon, V., Hilpert, M., Hunter, M. S., Jakobs, S., Koglin, J. E., Kovacsova, G., Lane, T. J., Lévy, B., Liang, M. N., Nass, K., Ridard, J., Robinson, J. S., Roome, C. M., Ruckebusch, C., Seaberg, M., Thepaut, M., Cammarata, M., Demachy, I., Field, M., Shoeman, R. L., Bourgeois, D., Colletier, J.-P., Schlichting, I. \& Weik, M. (2018). Nat. Chem. 10, 31-37.

Dashti, A., Mashayekhi, G., Shekhar, M., Ben Hail, D., Salah, S., Schwander, P., des Georges, A., Singharoy, A., Frank, J. \& Ourmazd, A. (2020). Nat. Commun. 11, 4734.

Decking, W., Abeghyan, S., Abramian, P., Abramsky, A., Aguirre, A., Albrecht, C., Alou, P., Altarelli, M., Altmann, P., Amyan, K., Anashin, V., Apostolov, E., Appel, K., Auguste, D., Ayvazyan, V., Baark, S., Babies, F., Baboi, N., Bak, P., Balandin, V., Baldinger, R., Baranasic, B., Barbanotti, S., Belikov, O., Belokurov, V., Belova, L., Belyakov, V., Berry, S., Bertucci, M., Beutner, B., Block, A., Blocher, M., Bockmann, T., Bohm, C., Bohnert, M., Bondar, V., Bondarchuk, E., Bonezzi, M., Borowiec, P., Bosch, C., Bosenberg, U., Bosotti, A., Bospflug, R., Bousonville, M., Boyd, E., Bozhko, Y., Brand, A., Branlard, J., Briechle, S., Brinker, F., Brinker, S., Brinkmann, R., Brockhauser, S., Brovko, O., Bruck, H., Brudgam, A., Butkowski, L., Buttner, T., Calero, J., Castro-Carballo, E., Cattalanotto, G., Charrier, J., Chen, J., Cherepenko, A., Cheskidov, V., Chiodini, M., Chong, A., Choroba, S., Chorowski, M., Churanov, D., Cichalewski, W., Clausen, M., Clement, W., Cloue, C., Cobos, J. A., Coppola, N., Cunis, S., Czuba, K., Czwalinna, M., D'Almagne, B., Dammann, J., Danared, H., Wagner, A. D., Delfs, A., Delfs, T., Dietrich, F., Dietrich, T., Dohlus, M., Dommach, M., Donat, A., Dong, X., Doynikov, N., Dressel, M., Duda, M., Duda, P., Eckoldt, H., Ehsan, W., Eidam, J., Eints, F., Engling, C., Englisch, U., Ermakov, A., Escherich, K., Eschke, J., Saldin, E., Faesing, M., Fallou, A., Felber, M., Fenner, M., Fernandes, B., Fernandez, J. M., Feuker, S., Filippakopoulos, K., Floettmann, K., Fogel, V., Fontaine, M., Frances, A., Martin, I. F., Freund, W., Freyermuth, T., Friedland, M., Frohlich, L., Fusetti, M., Fydrych, J., Gallas, A., Garcia, O., Garcia-Tabares, L., Geloni, G., Gerasimova, N., Gerth, C., Gessler, P., Gharibyan, V., Gloor, M., Glowinkowski, J., Goessel, A., Golebiewski, Z., Golubeva, N., Grabowski, W., Graeff, W., Grebentsov, A., Grecki, M., Grevsmuehl, T., Gross, M., GrosseWortmann, U., Grunert, J., Grunewald, S., Grzegory, P., Feng, G., Guler, H., Gusev, G., Gutierrez, J. L., Hagge, L., Hamberg, M., Hanneken, R., Harms, E., Hartl, I., Hauberg, A., Hauf, S., Hauschildt, J., Hauser, J., Havlicek, J., Hedqvist, A., Heidbrook, N., Hellberg, F., Henning, D., Hensler, O., Hermann, T., Hidvegi, A., Hierholzer, M., Hintz, H., Hoffmann, F., Hoffmann, M., Hoffmann, M., Holler, Y., Huning, M., Ignatenko, A., Ilchen, M., Iluk, A., Iversen, J., Iversen, J., Izquierdo, M., Jachmann, L., Jardon, N., Jastrow, U., Jensch, K., Jensen, J., Dotabek, M. J. O., Jidda, M., Jin, H., Johansson, N., Jonas, R., Kaabi, W., Kaefer, D., Kammering,
R., Kapitza, H., Karabekyan, S., Karstensen, S., Kasprzak, K., Katalev, V., Keese, D., Keil, B., Kholopov, M., Killenberger, M., Kitaev, B., Klimchenko, Y., Klos, R., Knebel, L., Koch, A., Koepke, M., Kohler, S., Kohler, W., Kohlstrunk, N., Konopkova, Z., Konstantinov, A., Kook, W., Koprek, W., Korfer, M., Korth, O., Kosarev, A., Kosinski, K., Kostin, D., Kot, Y., Kotarba, A., Kozak, T., Kozak, V., Kramert, R., Krasilnikov, M., Krasnov, A., Krause, B., Kravchuk, L., Krebs, O., Kretschmer, R., Kreutzkamp, J., Kroplin, O., Krzysik, K., Kube, G., Kuehn, H., Kujala, N., Kulikov, V., Kuzminych, V., La Civita, D., Lacroix, M., Lamb, T., Lancetov, A., Larsson, M., Le Pinvidic, D., Lederer, S., Lensch, T., Lenz, D., Leuschner, A., Levenhagen, F., Li, Y., Liebing, J., Lilje, L., Limberg, T., Lipka, D., List, B., Liu, J., Liu, S., Lorbeer, B., Lorkiewicz, J., Lu, H. H., Ludwig, F., Machau, K., Maciocha, W., Madec, C., Magueur, C., Maiano, C., Maksimova, I., Malcher, K., Maltezopoulos, T., Mamoshkina, E., Manschwetus, B., Marcellini, F., Marinkovic, G., Martinez, T., Martirosyan, H., Maschmann, W., Maslov, M., Matheisen, A., Mavric, U., Meissner, J., Meissner, K., Messerschmidt, M., Meyners, N., Michalski, G., Michelato, P., Mildner, N., Moe, M., Moglia, F., Mohr, C., Mohr, S., Moller, W., Mommerz, M., Monaco, L., Montiel, C., Moretti, M., Morozov, I., Morozov, P., Mross, D., Mueller, J., Muller, C., Muller, J., Muller, K., Munilla, J., Munnich, A., Muratov, V., Napoly, O., Naser, B., Nefedov, N., Neumann, R., Neumann, R., Ngada, N., Noelle, D., Obier, F., Okunev, I., Oliver, J. A., Omet, M., Oppelt, A., Ottmar, A., Oublaid, M., Pagani, C., Paparella, R., Paramonov, V., Peitzmann, C., Penning, J., Perus, A., Peters, F., Petersen, B., Petrov, A., Petrov, I., Pfeiffer, S., Pfluger, J., Philipp, S., Pienaud, Y., Pierini, P., Pivovarov, S., Planas, M., Plawski, E., Pohl, M., Polinski, J., Popov, V., Prat, S., Prenting, J., Priebe, G., Pryschelski, H., Przygoda, K., Pyata, E., Racky, B., Rathjen, A., Ratuschni, W., RegnaudCampderros, S., Rehlich, K., Reschke, D., Robson, C., Roever, J., Roggli, M., Rothenburg, J., Rusinski, E., Rybaniec, R., Sahling, H., Salmani, M., Samoylova, L., Sanzone, D., Saretzki, F., Sawlanski, O., Schaffran, J., Schlarb, H., Schlosser, M., Schlott, V., Schmidt, C., Schmidt-Foehre, F., Schmitz, M., Schmokel, M., Schnautz, T., Schneidmiller, E., Scholz, M., Schoneburg, B., Schultze, J., Schulz, C., Schwarz, A., Sekutowicz, J., Sellmann, D., Semenov, E., Serkez, S., Sertore, D., Shehzad, N., Shemarykin, P., Shi, L., Sienkiewicz, M., Sikora, D., Sikorski, M., Silenzi, A., Simon, C., Singer, W., Singer, X., Sinn, H., Sinram, K., Skvorodnev, N., Smirnow, P., Sommer, T., Sorokin, A., Stadler, M., Steckel, M., Steffen, B., Steinhau-Kuhl, N., Stephan, F., Stodulski, M., Stolper, M., Sulimov, A., Susen, R., Swierblewski, J., Sydlo, C., Syresin, E., Sytchev, V., Szuba, J., Tesch, N., Thie, J., Thiebault, A., Tiedtke, K., Tischhauser, D., Tolkiehn, J., Tomin, S., Tonisch, F., Toral, F., Torbin, I., Trapp, A., Treyer, D., Trowitzsch, G., Trublet, T., Tschentscher, T., Ullrich, F., Vannoni, M., Varela, P., Varghese, G., Vashchenko, G., Vasic, M., VazquezVelez, C., Verguet, A., Vilcins-Czvitkovits, S., Villanueva, R., Visentin, B., Viti, M., Vogel, E., Volobuev, E., Wagner, R., Walker, N., Wamsat, T., Weddig, H., Weichert, G., Weise, H., Wenndorf, R., Werner, M., Wichmann, R., Wiebers, C., Wiencek, M., Wilksen, T., Will, I., Winkelmann, L., Winkowski, M., Wittenburg, K., Witzig, A., Wlk, P., Wohlenberg, T., Wojciechowski, M., Wolff-Fabris, F., Wrochna, G., Wrona, K., Yakopov, M., Yang, B., Yang, F., Yurkov, M., Zagorodnov, I., Zalden, P., Zavadtsev, A., Zavadtsev, D., Zhirnov, A., Zhukov, A., Ziemann, V., Zolotov, A., Zolotukhina, N., Zummack, F. \& Zybin, D. (2020). Nat. Photonics, 14, 391-397.

Dods, R., Båth, P., Morozov, D., Gagnér, V. A., Arnlund, D., Luk, H. L., Kübel, J., Maj, M., Vallejos, A., Wickstrand, C., Bosman, R., Beyerlein, K. R., Nelson, G., Liang, M. N., Milathianaki, D., Robinson, J., Harimoorthy, R., Berntsen, P., Malmerberg, E., Johansson, L., Andersson, R., Carbajo, S., Claesson, E., Conrad, C. E., Dahl, P., Hammarin, G., Hunter, M. S., Li, C. F., Lisova, S., Royant, A., Safari, C., Sharma, A., Williams, G. J., Yefanov, O., Westenhoff, S., Davidsson, J., DePonte, D. P., Boutet, S., Barty, A., Katona, G., Groenhof, G., Brändén, G. \& Neutze, R. (2021). Nature, 589, 310-314. 
Eriksson, M. (2016). AIP Conf. Proc. 1741, 020001.

Fair, R. J. \& Tor, Y. (2014). Perspect. Medicin. Chem. 6, PMC.S14459.

Geremia, S., Campagnolo, M., Demitri, N. \& Johnson, L. N. (2006). Structure, 14, 393-400.

Gevorkov, Y., Yefanov, O., Barty, A., White, T. A., Mariani, V., Brehm, W., Tolstikova, A., Grigat, R.-R. \& Chapman, H. N. (2019). Acta Cryst. A75, 694-704.

Gourinchas, G., Etzl, S., Göbl, C., Vide, U., Madl, T. \& Winkler, A. (2017). Sci. Adv. 3, e1602498.

Grünbein, M. L., Gorel, A., Foucar, L., Carbajo, S., Colocho, W., Gilevich, S., Hartmann, E., Hilpert, M., Hunter, M., Kloos, M., Koglin, J. E., Lane, T. J., Lewandowski, J., Lutman, A., Nass, K., Nass Kovacs, G., Roome, C. M., Sheppard, J., Shoeman, R. L., Stricker, M., van Driel, T., Vetter, S., Doak, R. B., Boutet, S., Aquila, A., Decker, F. J., Barends, T. R. M., Stan, C. A. \& Schlichting, I. (2021). Nat. Commun. 12, 1672.

Han, H., Round, E., Schubert, R., Gül, Y., Makroczyová, J., Meza, D., Heuser, P., Aepfelbacher, M., Barák, I., Betzel, C., Fromme, P., Kursula, I., Nissen, P., Tereschenko, E., Schulz, J., Uetrecht, C., Ulicný, J., Wilmanns, M., Hajdu, J., Lamzin, V. S. \& Lorenzen, K. (2021). J. Appl. Cryst. 54, 7-21.

Hartmann, N., Helml, W., Galler, A., Bionta, M. R., Grünert, J. L., Molodtsov, S., Ferguson, K. R., Schorb, S., Swiggers, M. L., Carron, S., Bostedt, C., Castagna, J., Bozek, J., Glownia, J. M., Kane, D. J., Fry, A. R., White, W. E., Hauri, C. P., Feurer, T. \& Coffee, R. N. (2014). Nat. Photonics, 8, 706-709.

Holtorf, H., Reinbothe, S., Reinbothe, C., Bereza, B. \& Apel, K. (1995). Proc. Natl Acad. Sci. USA, 92, 3254-3258.

Hugonnet, J. E. \& Blanchard, J. S. (2007). Biochemistry, 46, 1199812004.

Imming, P., Sinning, C. \& Meyer, A. (2006). Nat. Rev. Drug Discov. 5, 821-834.

Ishigami, I., Lewis-Ballester, A., Echelmeier, A., Brehm, G., Zatsepin, N. A., Grant, T. D., Coe, J. D., Lisova, S., Nelson, G., Zhang, S., Dobson, Z. F., Boutet, S., Sierra, R. G., Batyuk, A., Fromme, P., Fromme, R., Spence, J. C. H., Ros, A., Yeh, S. R. \& Rousseau, D. L. (2019). Proc. Natl Acad. Sci. USA, 116, 3572-3577.

Jeffrey, G. A. (1997). An Introduction to Hydrogen Bonding. Oxford University Press.

Kern, J., Chatterjee, R., Young, I. D., Fuller, F. D., Lassalle, L., Ibrahim, M., Gul, S., Fransson, T., Brewster, A. S., Alonso-Mori, R., Hussein, R., Zhang, M., Douthit, L., de Lichtenberg, C., Cheah, M. H., Shevela, D., Wersig, J., Seuffert, I., Sokaras, D., Pastor, E., Weninger, C., Kroll, T., Sierra, R. G., Aller, P., Butryn, A., Orville, A. M., Liang, M., Batyuk, A., Koglin, J. E., Carbajo, S., Boutet, S., Moriarty, N. W., Holton, J. M., Dobbek, H., Adams, P. D., Bergmann, U., Sauter, N. K., Zouni, A., Messinger, J., Yano, J. \& Yachandra, V. K. (2018). Nature, 563, 421-425.

Kostov, K. S. \& Moffat, K. (2011). Biophys. J. 100, 440-449.

Kupitz, C., Basu, S., Grotjohann, I., Fromme, R., Zatsepin, N. A., Rendek, K. N., Hunter, M. S., Shoeman, R. L., White, T. A., Wang, D., James, D., Yang, J.-H., Cobb, D. E., Reeder, B., Sierra, R. G., Liu, H., Barty, A., Aquila, A. L., Deponte, D., Kirian, R. A., Bari, S., Bergkamp, J. J., Beyerlein, K. R., Bogan, M. J., Caleman, C., Chao, T.-C., Conrad, C. E., Davis, K. M., Fleckenstein, H., Galli, L., Hau-Riege, S. P., Kassemeyer, S., Laksmono, H., Liang, M., Lomb, L., Marchesini, S., Martin, A. V., Messerschmidt, M., Milathianaki, D., Nass, K., Ros, A., Roy-Chowdhury, S., Schmidt, K., Seibert, M., Steinbrener, J., Stellato, F., Yan, L., Yoon, C., Moore, T. A., Moore, A. L., Pushkar, Y., Williams, G. J., Boutet, S., Doak, R. B., Weierstall, U., Frank, M., Chapman, H. N., Spence, J. C. H. \& Fromme, P. (2014). Nature, 513, 261-265.

Kupitz, C., Olmos, J. L. Jr, Holl, M., Tremblay, L., Pande, K., Pandey, S., Oberthür, D., Hunter, M., Liang, M., Aquila, A., Tenboer, J., Calvey, G., Katz, A., Chen, Y., Wiedorn, M. O., Knoska, J., Meents, A., Majriani, V., Norwood, T., Poudyal, I., Grant, T., Miller, M. D., Xu, W., Tolstikova, A., Morgan, A., Metz, M., Martin-Garcia, J. M., Zook, J. D., Roy-Chowdhury, S., Coe, J., Nagaratnam, N., Meza, D.,
Fromme, R., Basu, S., Frank, M., White, T., Barty, A., Bajt, S., Yefanov, O., Chapman, H. N., Zatsepin, N., Nelson, G., Weierstall, U., Spence, J., Schwander, P., Pollack, L., Fromme, P., Ourmazd, A., Phillips, G. N. Jr \& Schmidt, M. (2017). Struct. Dyn. 4, 044003.

Li, J., Liu, Z., Tan, C., Guo, X., Wang, L., Sancar, A. \& Zhong, D. (2010). Nature, 466, 887-890.

Liebschner, D., Afonine, P. V., Baker, M. L., Bunkóczi, G., Chen, V. B., Croll, T. I., Hintze, B., Hung, L.-W., Jain, S., McCoy, A. J., Moriarty, N. W., Oeffner, R. D., Poon, B. K., Prisant, M. G., Read, R. J., Richardson, J. S., Richardson, D. C., Sammito, M. D., Sobolev, O. V., Stockwell, D. H., Terwilliger, T. C., Urzhumtsev, A. G., Videau, L. L., Williams, C. J. \& Adams, P. D. (2019). Acta Cryst. D75, 861-877.

Liebschner, D., Afonine, P. V., Moriarty, N. W., Poon, B. K., Sobolev, O. V., Terwilliger, T. C. \& Adams, P. D. (2017). Acta Cryst. D73, 148-157.

Lomb, L., Barends, T. R. M., Kassemeyer, S., Aquila, A., Epp, S. W., Erk, B., Foucar, L., Hartmann, R., Rudek, B., Rolles, D., Rudenko, A., Shoeman, R. L., Andreasson, J., Bajt, S., Barthelmess, M., Barty, A., Bogan, M. J., Bostedt, C., Bozek, J. D., Caleman, C., Coffee, R., Coppola, N., DePonte, D. P., Doak, R. B., Ekeberg, T., Fleckenstein, H., Fromme, P., Gebhardt, M., Graafsma, H., Gumprecht, L., Hampton, C. Y., Hartmann, A., Hauser, G., Hirsemann, H., Holl, P., Holton, J. M., Hunter, M. S., Kabsch, W., Kimmel, N., Kirian, R. A., Liang, M., Maia, F. R. N. C., Meinhart, A., Marchesini, S., Martin, A. V., Nass, K., Reich, C., Schulz, J., Seibert, M. M., Sierra, R., Soltau, H., Spence, J. C. H., Steinbrener, J., Stellato, F., Stern, S., Timneanu, N., Wang, X., Weidenspointner, G., Weierstall, U., White, T. A., Wunderer, C., Chapman, H. N., Ullrich, J., Strüder, L. \& Schlichting, I. (2011). Phys. Rev. B, 84, 214111.

Mancuso, A. P., Aquila, A., Batchelor, L., Bean, R. J., Bielecki, J., Borchers, G., Doerner, K., Giewekemeyer, K., Graceffa, R., Kelsey, O. D., Kim, Y., Kirkwood, H. J., Legrand, A., Letrun, R., Manning, B., Lopez Morillo, L., Messerschmidt, M., Mills, G., Raabe, S., Reimers, N., Round, A., Sato, T., Schulz, J., Signe Takem, C., Sikorski, M., Stern, S., Thute, P., Vagovič, P., Weinhausen, B. \& Tschentscher, T. (2019). J Synchrotron Rad, 26, 660-676.

Mariani, V., Morgan, A., Yoon, C. H., Lane, T. J., White, T. A., O’Grady, C., Kuhn, M., Aplin, S., Koglin, J., Barty, A. \& Chapman, H. N. (2016). J. Appl. Cryst. 49, 1073-1080.

Mehrabi, P., Schulz, E. C., Agthe, M., Horrell, S., Bourenkov, G., von Stetten, D., Leimkohl, J. P., Schikora, H., Schneider, T. R., Pearson, A. R., Tellkamp, F. \& Miller, R. J. D. (2019). Nat. Methods, 16, 979982.

Mehrabi, P., Schulz, E. C., Dsouza, R., Müller-Werkmeister, H. M., Tellkamp, F., Miller, R. J. D. \& Pai, E. F. (2019). Science, 365, 11671170.

Minor, W., Cymborowski, M., Otwinowski, Z. \& Chruszcz, M. (2006). Acta Cryst. D62, 859-866.

Moffat, K. (2001). Chem. Rev. 101, 1569-1582.

Murshudov, G. N., Skubák, P., Lebedev, A. A., Pannu, N. S., Steiner, R. A., Nicholls, R. A., Winn, M. D., Long, F. \& Vagin, A. A. (2011). Acta Cryst. D67, 355-367.

Nass, K. (2019). Acta Cryst. D75, 211-218.

Neutze, R., Wouts, R., van der Spoel, D., Weckert, E. \& Hajdu, J. (2000). Nature, 406, 752-757.

Nogly, P., Weinert, T., James, D., Carbajo, S., Ozerov, D., Furrer, A., Gashi, D., Borin, V., Skopintsev, P., Jaeger, K., Nass, K., Båth, P., Bosman, R., Koglin, J., Seaberg, M., Lane, T., Kekilli, D., Brünle, S., Tanaka, T., Wu, W., Milne, C., White, T., Barty, A., Weierstall, U., Panneels, V., Nango, E., Iwata, S., Hunter, M., Schapiro, I., Schertler, G., Neutze, R. \& Standfuss, J. (2018). Science, 361, eaat0094.

Olmos, J. L. Jr, Pandey, S., Martin-Garcia, J. M., Calvey, G., Katz, A., Knoska, J., Kupitz, C., Hunter, M. S., Liang, M., Oberthuer, D., Yefanov, O., Wiedorn, M., Heyman, M., Holl, M., Pande, K., Barty, A., Miller, M. D., Stern, S., Roy-Chowdhury, S., Coe, J., Nagaratnam, N., Zook, J., Verburgt, J., Norwood, T., Poudyal, I., 
Xu, D., Koglin, J., Seaberg, M. H., Zhao, Y., Bajt, S., Grant, T., Mariani, V., Nelson, G., Subramanian, G., Bae, E., Fromme, R., Fung, R., Schwander, P., Frank, M., White, T. A., Weierstall, U., Zatsepin, N., Spence, J., Fromme, P., Chapman, H. N., Pollack, L., Tremblay, L., Ourmazd, A., Phillips, G. N. Jr \& Schmidt, M. (2018). BMC Biol. 16, 59.

Pande, K., Hutchison, C. D. M., Groenhof, G., Aquila, A., Robinson, J. S., Tenboer, J., Basu, S., Boutet, S., DePonte, D., Liang, M., White, T., Zatsepin, N., Yefanov, O., Morozov, D., Oberthuer, D., Gati, C., Subramanian, G., James, D., Zhao, Y., Koralek, J., Brayshaw, J., Kupitz, C., Conrad, C., Roy-Chowdhury, S., Coe, J. D., Metz, M., Xavier, P. L., Grant, T. D., Koglin, J. E., Ketawala, G., Fromme, R., Šrajer, V., Henning, R., Spence, J. C. H., Ourmazd, A., Schwander, P., Weierstall, U., Frank, M., Fromme, P., Barty, A., Chapman, H. N., Moffat, K., van Thor, J. J. \& Schmidt, M. (2016). Science, 352, 725729.

Pandey, S., Bean, R., Sato, T., Poudyal, I., Bielecki, J., Cruz Villarreal, J., Yefanov, O., Mariani, V., White, T. A., Kupitz, C., Hunter, M., Abdellatif, M. H., Bajt, S., Bondar, V., Echelmeier, A., Doppler, D., Emons, M., Frank, M., Fromme, R., Gevorkov, Y., Giovanetti, G., Jiang, M., Kim, D., Kim, Y., Kirkwood, H., Klimovskaia, A., Knoska, J., Koua, F. H. M., Letrun, R., Lisova, S., Maia, L., Mazalova, V., Meza, D., Michelat, T., Ourmazd, A., Palmer, G., Ramilli, M., Schubert, R., Schwander, P., Silenzi, A., SztukDambietz, J., Tolstikova, A., Chapman, H. N., Ros, A., Barty, A., Fromme, P., Mancuso, A. P. \& Schmidt, M. (2020). Nat. Methods, 17, 73-78.

Ramakrishnan, S., Stagno, J. R., Conrad, C. E., Ding, J., Yu, P., Bhandari, Y. R., Lee, Y. T., Pauly, G., Yefanov, O., Wiedorn, M. O., Knoska, J., Oberthür, D., White, T. A., Barty, A., Mariani, V., Li, C., Brehm, W., Heinz, W. F., Magidson, V., Lockett, S., Hunter, M. S., Boutet, S., Zatsepin, N. A., Zuo, X., Grant, T. D., Pandey, S., Schmidt, M., Spence, J. C. H., Chapman, H. N. \& Wang, Y.-X. (2021). Nat. Commun. 12, 1762.

Ren, Z., Perman, B., Šrajer, V., Teng, T.-Y., Pradervand, C., Bourgeois, D., Schotte, F., Ursby, T., Kort, R., Wulff, M. \& Moffat, K. (2001). Biochemistry, 40, 13788-13801.

Schmidt, M. (2008). Ultrashort Laser Pulses in Medicine and Biology, edited by M. Braun, P. Gilch \& W. Zinth, pp. 201-241. Berlin, Heidelberg, New York: Springer

Schmidt, M. (2013). Adv. Condens. Matter Phys. 2013, 1-10.

Schmidt, M. (2020). Crystals, 10, 116.

Schmidt, M., Rajagopal, S., Ren, Z. \& Moffat, K. (2003). Biophys. J. 84, 2112-2129.

Schmidt, M., Srajer, V., Henning, R., Ihee, H., Purwar, N., Tenboer, J. \& Tripathi, S. (2013). Acta Cryst. D69, 2534-2542.

Skopintsev, P., Ehrenberg, D., Weinert, T., James, D., Kar, R. K., Johnson, P. J. M., Ozerov, D., Furrer, A., Martiel, I., Dworkowski, F., Nass, K., Knopp, G., Cirelli, C., Arrell, C., Gashi, D., Mous, S., Wranik, M., Gruhl, T., Kekilli, D., Brünle, S., Deupi, X., Schertler, G. F. X., Benoit, R. M., Panneels, V., Nogly, P., Schapiro, I., Milne, C., Heberle, J. \& Standfuss, J. (2020). Nature, 583, 314-318.

Smith, T., Wolff, K. A. \& Nguyen, L. (2013). Curr. Top. Microbiol. Immunol. 374, 53-80.

Sorigué, D., Hadjidemetriou, K., Blangy, S., Gotthard, G., Bonvalet, A., Coquelle, N., Samire, P., Aleksandrov, A., Antonucci, L., Benachir, A., Boutet, S., Byrdin, M., Cammarata, M., Carbajo, S., Cuiné, S., Doak, R. B., Foucar, L., Gorel, A., Grünbein, M., Hartmann, E., Hienerwadel, R., Hilpert, M., Kloos, M., Lane, T. J., Légeret, B., Legrand, P., Li-Beisson, Y., Moulin, S. L. Y., Nurizzo, D., Peltier, G., Schirò, G., Shoeman, R. L., Sliwa, M., Solinas, X., Zhuang, B., Barends, T. R. M., Colletier, J., Joffre, M., Royant, A., Berthomieu, C., Weik, M., Domratcheva, T., Brettel, K., Vos, M. H., Schlichting, I., Arnoux, P., Müller, P. \& Beisson, F. (2021). Science, 372, eabd5687.

Sorigué, D., Légeret, B., Cuiné, S., Blangy, S., Moulin, S., Billon, E., Richaud, P., Brugière, S., Couté, Y., Nurizzo, D., Müller, P., Brettel,
K., Pignol, D., Arnoux, P., Li-Beisson, Y., Peltier, G. \& Beisson, F. (2017). Science, 357, 903-907.

Šajer, V. \& Schmidt, V. (2017). J. Phys. D Appl. Phys. 50, 373001.

Stagno, J. R., Liu, Y., Bhandari, Y. R., Conrad, C. E., Panja, S., Swain, M., Fan, L., Nelson, G., Li, C., Wendel, D. R., White, T. A., Coe, J. D., Wiedorn, M. O., Knoska, J., Oberthuer, D., Tuckey, R. A., Yu, P., Dyba, M., Tarasov, S. G., Weierstall, U., Grant, T. D., Schwieters, C. D., Zhang, J., Ferré-D'Amaré, A. R., Fromme, P., Draper, D. E., Liang, M., Hunter, M. S., Boutet, S., Tan, K., Zuo, X., Ji, X., Barty, A., Zatsepin, N. A., Chapman, H. N., Spence, J. C. H., Woodson, S. A. \& Wang, Y.-X. (2017). Nature, 541, 242-246.

Takala, H., Björling, A., Berntsson, O., Lehtivuori, H., Niebling, S., Hoernke, M., Kosheleva, I., Henning, R., Menzel, A., Ihalainen, J. A. \& Westenhoff, S. (2014). Nature, 509, 245-248.

Tassoni, R., Blok, A., Pannu, N. S. \& Ubbink, M. (2019). Biochemistry, 58, 997-1009.

Tenboer, J., Basu, S., Zatsepin, N., Pande, K., Milathianaki, D., Frank, M., Hunter, M., Boutet, S., Williams, G. J., Koglin, J. E., Oberthuer, D., Heymann, M., Kupitz, C., Conrad, C., Coe, J., Roy-Chowdhury, S., Weierstall, U., James, D., Wang, D., Grant, T., Barty, A., Yefanov, O., Scales, J., Gati, C., Seuring, C., Srajer, V., Henning, R., Schwander, P., Fromme, R., Ourmazd, A., Moffat, K., Van Thor, J. J., Spence, J. C. H., Fromme, P., Chapman, H. N. \& Schmidt, M. (2014). Science, 346, 1242-1246.

Totir, M. A., Helfand, M. S., Carey, M. P., Sheri, A., Buynak, J. D., Bonomo, R. A. \& Carey, P. R. (2007). Biochemistry, 46, 8980-8987.

Tremblay, L. W., Xu, H. \& Blanchard, J. S. (2010). Biochemistry, 49, 9685-9687.

Tzeng, S. R. \& Kalodimos, C. G. (2012). Nature, 488, 236-240.

Vogt, A. D. \& Di Cera, E. (2012). Biochemistry, 51, 5894-5902.

Wanzenberg, R., Agapov, I., Brefeld, W., Brinkmann, R., Chae, Y., Chao, H., Keil, J., Gavaldà, X. N., Röhlsberger, R., Schroer, C. G., Tischer, M. \& Weckert, E. (2019). AIP Conf. Proc. 2054, 030002.

White, T. A., Mariani, V., Brehm, W., Yefanov, O., Barty, A., Beyerlein, K. R., Chervinskii, F., Galli, L., Gati, C., Nakane, T., Tolstikova, A., Yamashita, K., Yoon, C. H., Diederichs, K. \& Chapman, H. N. (2016). J. Appl. Cryst. 49, 680-689.

Wiedorn, M. O., Awel, S., Morgan, A. J., Ayyer, K., Gevorkov, Y., Fleckenstein, H., Roth, N., Adriano, L., Bean, R., Beyerlein, K. R., Chen, J., Coe, J., Cruz-Mazo, F., Ekeberg, T., Graceffa, R., Heymann, M., Horke, D. A., Knoška, J., Mariani, V., Nazari, R., Oberthür, D., Samanta, A. K., Sierra, R. G., Stan, C. A., Yefanov, O., Rompotis, D., Correa, J., Erk, B., Treusch, R., Schulz, J., Hogue, B. G., Gañán-Calvo, A. M., Fromme, P., Küpper, J., Rode, A. V., Bajt, S., Kirian, R. A. \& Chapman, H. N. (2018). IUCrJ, 5, 574-584. Wiedorn, M. O., Oberthür, D., Bean, R., Schubert, R., Werner, N., Abbey, B., Aepfelbacher, M., Adriano, L., Allahgholi, A., AlQudami, N., Andreasson, J., Aplin, S., Awel, S., Ayyer, K., Bajt, S., Barák, I., Bari, S., Bielecki, J., Botha, S., Boukhelef, D., Brehm, W., Brockhauser, S., Cheviakov, I., Coleman, M. A., Cruz-Mazo, F., Danilevski, C., Darmanin, C., Doak, R. B., Domaracky, M., Dörner, K., Du, Y., Fangohr, H., Fleckenstein, H., Frank, M., Fromme, P., Gañán-Calvo, A. M., Gevorkov, Y., Giewekemeyer, K., Ginn, H. M., Graafsma, H., Graceffa, R., Greiffenberg, D., Gumprecht, L., Göttlicher, P., Hajdu, J., Hauf, S., Heymann, M., Holmes, S., Horke, D. A., Hunter, M. S., Imlau, S., Kaukher, A., Kim, Y., Klyuev, A., Knoška, J., Kobe, B., Kuhn, M., Kupitz, C., Küpper, J., Lahey-Rudolph, J. M., Laurus, T., Le Cong, K., Letrun, R., Xavier, P. L., Maia, L., Maia, F., Mariani, V., Messerschmidt, M., Metz, M., Mezza, D., Michelat, T., Mills, G., Monteiro, D. C. F., Morgan, A., Mühlig, K., Munke, A., Münnich, A., Nette, J., Nugent, K. A., Nuguid, T., Orville, A. M., Pandey, S., Pena, G., Villanueva-Perez, P., Poehlsen, J., Previtali, G., Redecke, L., Riekehr, W. M., Rohde, H., Round, A., Safenreiter, T., Sarrou, I., Sato, T., Schmidt, M., Schmitt, B., Schönherr, R., Schulz, J., Sellberg, J. A., Seibert, M. M., Seuring, C., Shelby, M. L., Shoeman, R. L., Sikorski, M., Silenzi, A., Stan, C. A., Shi, X., Stern, S., Sztuk-Dambietz, J., Szuba, J., Tolstikova, A., Trebbin, M., Trunk, U., Vagovic, P., Ve, T., 
Weinhausen, B., White, T. A., Wrona, K., Xu, C., Yefanov, O., Zatsepin, N., Zhang, J., Perbandt, M., Mancuso, A. P., Betzel, C., Chapman, H. \& Barty, A. (2018). Nat. Commun. 9, 4025.

Winn, M. D., Ballard, C. C., Cowtan, K. D., Dodson, E. J., Emsley, P., Evans, P. R., Keegan, R. M., Krissinel, E. B., Leslie, A. G. W., McCoy, A., McNicholas, S. J., Murshudov, G. N., Pannu, N. S., Potterton, E. A., Powell, H. R., Read, R. J., Vagin, A. \& Wilson, K. S. (2011). Acta Cryst. D67, 235-242.

Yefanov, O., Mariani, V., Gati, C., White, T. A., Chapman, H. N. \& Barty, A. (2015). Opt. Express, 23, 28459-28470.

Yefanov, O., Oberthür, D., Bean, R., Wiedorn, M. O., Knoska, J., Pena, G., Awel, S., Gumprecht, L., Domaracky, M., Sarrou, I., Lourdu Xavier, P., Metz, M., Bajt, S., Mariani, V., Gevorkov, Y., White, T. A., Tolstikova, A., Villanueva-Perez, P., Seuring, C., Aplin, S., Estillore, A. D., Küpper, J., Klyuev, A., Kuhn, M., Laurus,
T., Graafsma, H., Monteiro, D. C. F., Trebbin, M., Maia, F. R. N. C., Cruz-Mazo, F., Gañán-Calvo, A. M., Heymann, M., Darmanin, C., Abbey, B., Schmidt, M., Fromme, P., Giewekemeyer, K., Sikorski, M., Graceffa, R., Vagovic, P., Kluyver, T., Bergemann, M., Fangohr, H., Sztuk-Dambietz, J., Hauf, S., Raab, N., Bondar, V., Mancuso, A. P., Chapman, H. \& Barty, A. (2019). Struct. Dyn. 6, 064702.

Yun, J.-H., Li, X., Yue, J., Park, J.-H., Jin, Z., Li, C., Hu, H., Shi, Y., Pandey, S., Carbajo, S., Boutet, S., Hunter, M. S., Liang, M., Sierra, R. G., Lane, T. J., Zhou, L., Weierstall, U., Zatsepin, N. A., Ohki, M., Tame, J. R. H., Park, S. Y., Spence, J. C. H., Zhang, W., Schmidt, M., Lee, W. \& Liu, H. (2021). Proc. Natl Acad. Sci. USA, 118, e2020486118.

Zaitsev-Doyle, J. J., Puchert, A., Pfeifer, Y., Yan, H., Yorke, B. A., Müller-Werkmeister, H. M., Uetrecht, C., Rehbein, J., Huse, N., Pearson, A. R. \& Sans, M. (2019). RSC Adv. 9, 8695-8699. 